\title{
Two-dimensional arrangements of
}

\section{bis(haloethynyl)benzenes combining halogen and}

\section{hydrogen interactions}

\author{
Lucía González, ${ }^{\mathrm{a}, \mathrm{d}}$ Rosa MaríaTejedor, ${ }^{\mathrm{h}}$ Eva Royo, ${ }^{\mathrm{a}, \mathrm{d}}$ Blanca Gaspar, ${ }^{\mathrm{a}, \mathrm{d}}$ Julen Munárriz, ${ }^{\mathrm{c}, \mathrm{g}}$ Anjana \\ Chanthapally, ${ }^{\mathrm{d}}$ José Luis Serrano, ${ }^{\mathrm{b}, \mathrm{f}}$ Jagadese J.Vittal, ${ }^{\mathrm{d}}$ Santiago Uriel ${ }^{\mathrm{a}}{ }^{*}$
}
a Dpto. Química Orgánica, Escuela de Ingeniería y Arquitectura ${ }_{2}$ Universidad de Zaragoza, Zaragoza, Spain.

${ }^{\mathrm{b}}$ Dpto. Química Orgánica, Facultad de Ciencias, Universidad de Zaragoza, Zaragoza, Spain.

${ }^{c}$ Dpto. Química Física, Facultad de Ciencias, Universidad de Zaragoza, Zaragoza, Spain.

${ }^{d}$ Department of Chemistry, National University of Singapore, Singapore.

f Instituto de Nanociencia de Aragón, Universidad de Zaragoza, Zaragoza, Spain.

g Instituto de Biocomputación y Física de los Sistemas Complejos, Universidad de Zaragoza, Zaragoza, Spain.

${ }^{\text {h }}$ Centro Universitario de la Defensa, Academia General Militar, Zaragoza, Spain.

RECEIVED DATE (to be automatically inserted after your manuscript is accepted if required according to the journal that you are submitting your paper to)

CORRESPONDING AUTHOR FOOTNOTE

* To whom correspondence should be addressed. Phone: +34-876-555388. Fax: +34-976-762686. Email: suriel@unizar.es 


\begin{abstract}
The electronic distribution of some haloethynylbenzene derivatives may favour the formation of two-dimensional organizations by combining halogen and hydrogen bonds. In order to highlight this strategy we have prepared seven cocrystals and analyzed their structures. 1,4Bis(iodoethynyl)benzene $\quad(p$-BIB), $\quad$ 1,4-bis(bromoethynyl)benzene $\quad(p$-BBrB) $\quad$ and $\quad 1,3-$ bis(iodoethynyl)benzene ( $m$-BIB) were used as halogen bond donors and 1,2-bis(4-pyridyl)ethylene (BPE), pyridazine, propanone, hexamethylenetetramine (HTMA) and 2,8-dimethyl-6H,12H-5,11methanodibenzo[b,f][1,5]diazocine (Tröger's base, TB) were employed as halogen bond acceptors. The crystal structures of seven halogen-bonded complexes show $\mathrm{C}-\mathrm{X} \cdots \mathrm{Y}(\mathrm{X}=\mathrm{I}, \mathrm{Br} ; \mathrm{Y}=\mathrm{N}, \mathrm{O})$ distances shorter than the sum of the van der Waals radii and six of them contain the edge-to-edge $\mathrm{C}-\mathrm{H} \cdots \mathrm{X}(\mathrm{X}=\mathrm{I}, \mathrm{Br})$ supramolecular hydrogen bond synthon. The stabilization energies with BSSE correction of hydrogen bond synthons have been determined by DFT calculations, and they are in the range 2.9 to $5.7 \mathrm{kcalmol}^{-1}$. To gain a deeper understanding of these interactions, Non-Covalent Interactions (NCI) methodology was also applied.
\end{abstract}

\title{
Introduction
}

The arrangement adopted by individual molecules in the solid state is the key to material performance in all molecular organic devices. For instance, good electronic performance requires the molecules to adopt a coplanar arrangement and stack to promote effective electronic coupling between the $\pi$-systems of individual molecules. ${ }^{1}$ However, highly conjugated small molecules very often adopt herringbone packing motifs due to edge-to-face interactions, such as $\mathrm{C}-\mathrm{H} \cdots \pi$, which in

many cases precludes effective electronic coupling between the $\pi$-systems of individual molecules. ${ }^{1-2}$ It is therefore very important to overcome this tendency in the development of organic materials. There are very few generally applicable strategies to achieve this goal, ${ }^{3}$ but hydrogen bonding is one class of edge-to-edge interaction for which there are several examples that yield intermolecular 
overlap of $\pi$-orbitals of highly conjugated small molecules. ${ }^{4,5}$ In this context, we propose haloethynylbenzene derivatives as tectons that may promote the formation of edge-to-edge hydrogen bonds.

Haloalkynes have a well-established role in synthetic organic chemistry, ${ }^{6}$ but their application in supramolecular chemistry is less well developed despite their long history. ${ }^{7-8,9}$ Theoretical, statistical and crystallographic studies demonstrate that the $s p$ hybridization of the carbon atom adjacent to the halogen allows the ethynyl-based iodine atom to display a polar $\sigma$-hole. ${ }^{10-13}$ This is of comparable magnitude to fluorine-substituted iodocarbons, which are the most widely used halogen bonding donors. ${ }^{14}$ As a consequence, haloalkynes can form strong, directional and selective halogen bonds, thus making them suitable for geometry-based design. In addition, both organic halogen and ethynyl groups have a cylindrical negative charge density distribution. ${ }^{15}$ Hence, electropositive atoms or groups will be able to approach the halogen atom and/or ethynyl group in the equatorial direction. Thereby, haloethynylbenzenes may lead to edge-to-edge intermolecular interactions between haloethynyl groups and adjacent phenyl rings through weak $\mathrm{C}-\mathrm{H} \cdots \mathrm{X}(\mathrm{X}=\mathrm{I}, \mathrm{Br})$ and/or $\mathrm{C}-\mathrm{H} \cdots \pi_{(\text {alkyne) }}$ hydrogen bonds that favor the formation of coplanar structures. ${ }^{16}$ These supramolecular synthons ${ }^{17}$ are present but have not been described in structures of 1,4bis(haloethynyl)benzene $(\mathrm{X}=\mathrm{I}, \mathrm{Br})^{18}$ and 1,2-bis(iodoethynyl)benzene-bis(N,N-dimethylpyridin-4amine) cocrystal. ${ }^{12}$ Furthermore, Lackinger and co-workers recently proposed a similar synthon to explain the bidimensional arrangement of 1,4-diethynylbenzene on a $\mathrm{Cu}(111)$ surface. $^{5}$

In an effort to demonstrate the ability of bis(haloethynyl)benzene derivatives to prevent the formation of herringbone packing and promote the formation of two-dimensional organizations by combining halogen and hydrogen bonds, we cocrystallized ditopic 1,4- and 1,3bis(haloethynyl)benzene derivatives, XB donors, with ditopic nitrogen bases (Scheme 1). Having obtained the initial results for the model systems $\mathbf{1}-\mathbf{3}$, we introduced pyridazine (cocrystal 4) and propanone (cocrystal 5) as halogen bond acceptor coformers in order to expand the scope of 
application of our approach. Heretofore, cocrystals of bis(haloethynyl)benzene derivatives in which carbonyl group acts as halogen bonding acceptor have not been described, but the halogen bond has been employed for the molecular recognition of acetone ${ }^{19}$ and to activate carbonyl compounds. ${ }^{20}$ Finally, non-planar halogen bond acceptors (hexamethylenetetramine, HTMA) and 2,8-dimethyl$6 H, 12 H-5,11$-methanodibenzo[ $b, f][1,5]$ diazocine (Tröger's base, TB) were used in which the nitrogen atoms have $s p^{3}$ hybridization, unlike the acceptors previously used, to study their effect on the supramolecular organization.

In this contribution, the supramolecular organization is interpreted through the analysis of morphological diversity, Hirshfeld surface analysis and quantum chemical theoretical calculations, which were carried out in an effort to gain greater insights into the packing and energetic aspects of molecular crystal structures.

Two different computational approaches were applied to the systems under study. On the one hand, interaction energies between dimers extracted from the experimental crystal were computed using DFT methodology. This way, it is possible to quantify the energetic stabilization that happens when two subunits interact with each other, allowing identify the systems with most favorable interactions. However, this interaction energy does not provide information about directionality nor about the specific atoms that take part in the interactions. As far as weak non-covalent interactions are considered, Non-Covalent Interactions (NCI) methodology ${ }^{21-22}$ provides valuable complementary information as it allows to graphically visualize and characterize them, ${ }^{23}$ since, as the name suggests, the method has been specifically developed to reveal non-covalent interactions, such as hydrogen bonds, in which we are interested. 


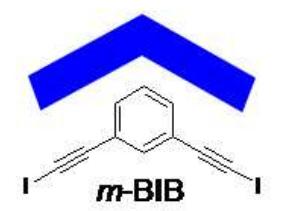

\section{Halogen Bond Donors Halogen Bond Acceptors} Halogen Bond Complexes
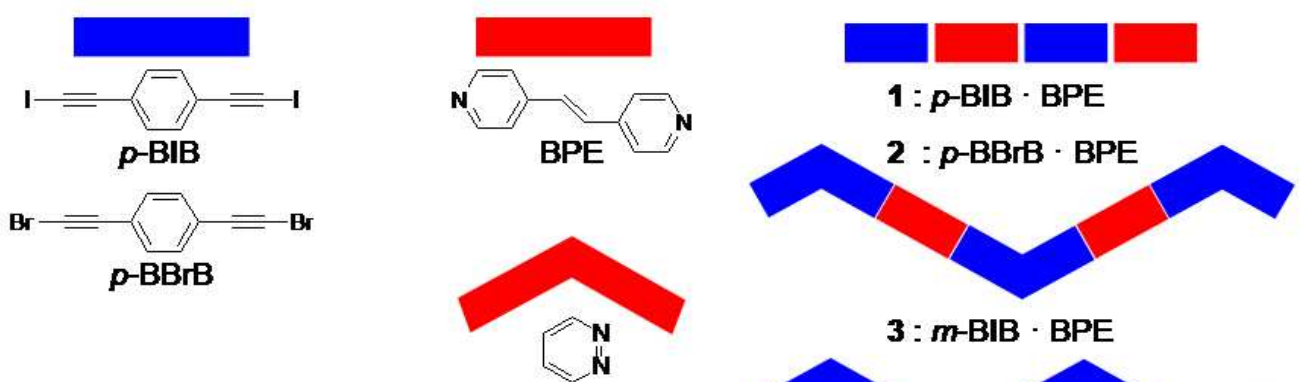
Pyridazine

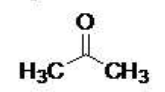

Propanone
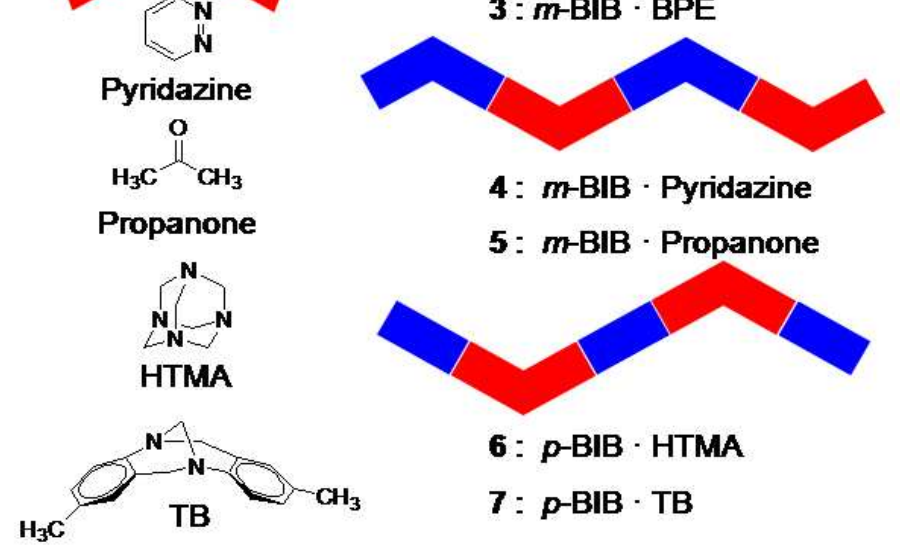

4: $m$-BIB - Pyridazine

5: $m$-BIB - Propanone

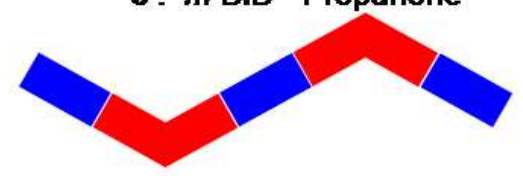

6: p-BIB - HTMA

7: $p$-BIB $\cdot$ TB

Scheme 1. Schematic representation of structures obtained from linear and angular halogen bond donors (blue) and ditopic acceptors (red).

\section{Materials and Methods}

Halogen bond donors were prepared from commercially available 1,4- and 1,3-diethynylbenzene by previously described methods. ${ }^{24}$ All halogen bond acceptors and solvents were commercially available and were used as received without further purification.

\section{X-ray crystallography}

X-ray quality single crystals were obtained by slow evaporation of $1 \mathrm{mmol}$ solutions of the halogen bond donor and acceptor dissolved in approximately $20 \mathrm{~mL}$ of dichloromethane. X-ray diffraction experiments were carried out on Oxford-diffraction Xcalibur S and Bruker AXS D8 Venture diffractometers. Mo- $\mathrm{K}_{\alpha}$ radiation was used for data collection for all crystals except $\mathbf{6}$, for 
which $\mathrm{Cu}-\mathrm{K}_{\alpha}$ radiation was used. The software packages $\mathrm{XSCANS}^{25}$ and CrysAlis ${ }^{26}$ were used to process data.

The final cell parameters were obtained by global refinement of reflections obtained from integration of all the frames data. The structures were solved by direct methods and refined by the full-matrix method based on $\mathrm{F}^{2}$ using the SHELXTL program. ${ }^{27}$ The non-hydrogen atoms of structures 1 to 7 were refined anisotropically, the hydrogen atoms were observed in difference electron density maps or included at idealized positions by using a riding model and refined isotropically. The crystal parameters and basic information relating data collection and structure refinement for compounds $\mathbf{1} \mathbf{- 7}$ are summarized in Table 1. 
Table 1. Crystallographic data for $\mathbf{1}$ to 3

\begin{tabular}{|c|c|c|c|}
\hline Compound & 1 & 2 & 3 \\
\hline Empirical formula & $\mathrm{C}_{22} \mathrm{H}_{14} \mathrm{I}_{2} \mathrm{~N}_{2}$ & $\mathrm{C}_{22} \mathrm{H}_{14} \mathrm{Br}_{2} \mathrm{~N}_{2}$ & $\mathrm{C}_{22} \mathrm{H}_{14} \mathrm{I}_{2} \mathrm{~N}_{2}$ \\
\hline Formula weight & 560.15 & 466.17 & 560.15 \\
\hline Crystal System & Triclinic & Triclinic & Monoclinic \\
\hline $\mathrm{a}, \AA$ & $7.1304(8)$ & $6.905(3)$ & $18.0909(10)$ \\
\hline $\mathrm{b}, \AA$ & $8.3566(9)$ & $8.325(4)$ & 7.0967(4) \\
\hline c,$\AA$ & $8.9642(10)$ & $8.847(4)$ & $15.9290(9)$ \\
\hline$\alpha, \operatorname{deg}$ & $94.384(2)$ & 93.931(8) & 90.0 \\
\hline$\beta, \operatorname{deg}$ & $108.595(2)$ & $108.073(7)$ & $105.122(2)$ \\
\hline$\gamma, \operatorname{deg}$ & $106.701(2)$ & $106.888(8)$ & 90.0 \\
\hline $\mathrm{V}, \AA^{3}$ & $476.52(9)$ & $455.5(4)$ & 1974.24(19) \\
\hline T, K & $100(2)$ & $100(2)$ & $100(2)$ \\
\hline Space group & P-1 & P-1 & $\mathrm{C} 2 / \mathrm{c}$ \\
\hline $\mathrm{Z}$ & 1 & 1 & 4 \\
\hline$\mu(\mathrm{Mo} \mathrm{K} \alpha), \mathrm{mm}^{-1}$ & 3.308 & 4.456 & 3.193 \\
\hline$\theta$ range, deg & 2.44 to 27.55 & 2.46 to 27.53 & 2.33 to 28.31 \\
\hline Refl. collected & 6153 & 5915 & 19327 \\
\hline Uniq reflect / $R_{\text {int }}$ & $2189 / 0.0322$ & $2081 / 0.0327$ & $2454 / 0.0325$ \\
\hline$R 1 / w R 2(\mathrm{I}>2 \sigma)$ & $0.0250 / 0.0605$ & $0.0252 / 0.0647$ & $0.0219 / 0.0444$ \\
\hline$R 1 / w R 2$ (all data) & $0.0269 / 0.0615$ & $0.0268 / 0.0656$ & $0.0317 / 0.0468$ \\
\hline Max. shift/esd & 0.001 & 0.001 & 0.001 \\
\hline Residual $\rho / \mathrm{e} \AA^{-3}$ & 1.151 and -0.561 & 0.488 and -0.422 & 0.710 and -0.408 \\
\hline
\end{tabular}


Table 1 (cont.). Crystallographic data for 4 to 7

\begin{tabular}{|c|c|c|c|c|}
\hline Compound & 4 & 5 & 6 & 7 \\
\hline Empirical formula & $\mathrm{C}_{14} \mathrm{H}_{8} \mathrm{I}_{2} \mathrm{~N}_{2}$ & $\mathrm{C}_{13} \mathrm{H}_{10} \mathrm{I}_{2} \mathrm{O}$ & $\mathrm{C}_{16} \mathrm{H}_{16} \mathrm{I}_{2} \mathrm{~N}_{4}$ & $\mathrm{C}_{27} \mathrm{H}_{22} \mathrm{I}_{2} \mathrm{~N}_{2}$ \\
\hline Formula weight & 458.02 & 436.01 & 518.13 & 628.27 \\
\hline Crystal System & Orthorhombic & Monoclinic & Orthorhombic & Monoclinic \\
\hline $\mathrm{a}, \AA$ & $12.56832(18)$ & $4.2101(2)$ & $9.2510(6)$ & $9.9879(4)$ \\
\hline $\mathrm{b}, \AA$ & $14.3151(2)$ & $14.0293(7)$ & $7.8618(4)$ & $23.8828(7)$ \\
\hline $\mathrm{c}, \AA$ & $7.96899(12)$ & $11.6962(6)$ & $23.920(11)$ & $10.9064(4)$ \\
\hline$\alpha, \operatorname{deg}$ & 90.0 & 90.0 & 90.0 & 90.0 \\
\hline$\beta, \operatorname{deg}$ & 90.0 & $90.593(5)$ & 90.0 & $111.637(4)$ \\
\hline$\gamma, \operatorname{deg}$ & 90.0 & 90.0 & 90.0 & 90.0 \\
\hline $\mathrm{V}, \AA^{3}$ & $1433.76(4)$ & $690.80(6)$ & $1739.7(8)$ & $2418.29(15)$ \\
\hline $\mathrm{T}, \mathrm{K}$ & $100(2)$ & $293(2)$ & $298(2)$ & $150(2)$ \\
\hline Space group & Pnma & $\mathrm{P} 2_{1} / \mathrm{n}$ & $\mathrm{Cmcm}$ & $\mathrm{P} 2{ }_{1} / \mathrm{n}$ \\
\hline Z & 4 & 2 & 4 & 4 \\
\hline$\mu($ Mo K $\alpha), \mathrm{mm}^{-1}$ & $34.318^{(\mathrm{a})}$ & 4.530 & 3.617 & 2.617 \\
\hline$\theta$ range, deg & 6.18 to 74.15 & 2.90 to 27.16 & 3.40 to 26.37 & 2.92 to 26.37 \\
\hline Refl. collected & 9800 & 2330 & 5351 & 9485 \\
\hline Uniq reflect / $R_{\text {int }}$ & $1509 / 0.0415$ & $1322 / 0.0287$ & $968 / 0.0351$ & 4947 / 0.0279 \\
\hline$R 1 / w R 2(\mathrm{I}>2 \sigma)$ & $0.0272 / 0.0675$ & $0.0275 / 0.0561$ & $0.0243 / 0.0538$ & $0.0374 / 0.0741$ \\
\hline$R 1 / w R 2$ (all data) & 0.0284 / 0.0689 & $0.0355 / 0.0605$ & $0.0393 / 0.0574$ & 0.0584 / 0.0839 \\
\hline Max. shift/esd & 0.001 & 0.001 & 0.001 & 0.001 \\
\hline Residual $\rho / \mathrm{e} \AA^{-3}$ & 0.853 and -1.968 & 0.785 and -0.799 & 0.512 and -0.407 & 0.592 and -0.599 \\
\hline
\end{tabular}

(a) $\mathrm{Cu} \mathrm{K \alpha}$

\section{Hirshfeld Surface Analysis}

Hirshfeld surfaces and the associated fingerprint plots were calculated using CrystalExplorer, ${ }^{28}$ which accepts a structure input file in the CIF format. Bond lengths to hydrogen atoms were set to typical neutron values $(\mathrm{C}-\mathrm{H}=1.083 \AA)$. The distance from the Hirshfeld surface to the nearest atoms outside and inside the surface are characterized by the quantities $d_{e}$ and $d_{i}$, respectively, and the normalized contact distance based on these, $\left.d_{\text {norm }}=\left(d_{i}-\mathrm{r}_{\mathrm{i}}^{\mathrm{vdW}}\right) / \mathrm{r}_{\mathrm{i}}^{\mathrm{vdW}}+\left(d_{e}-\mathrm{r}_{\mathrm{e}}^{\mathrm{vdW}}\right) / \mathrm{r}_{\mathrm{e}}^{\mathrm{vdW}}\right)$, where 
$r_{i}{ }^{\mathrm{dW}}$ and $r_{e}{ }^{\mathrm{vdW}}$ are the van der Waals radii of the atoms. The 2D histograms, fingerprints, plot distance external to the surface $\left(d_{e}\right)$ versus distance internal to the surface $\left(d_{i}\right)$ : is the distance from the surface to the nearest atom in the molecule itself.

\section{Computational Methods}

Quantum chemical calculations were performed using the Gaussian $09^{29}$ suite of programs. Single point calculations of dimers extracted from experimental crystal structures were carried out by the gas phase B3LYP method, ${ }^{30}$ with the van der Waals dispersion correction, ${ }^{31}$ employing the 6$311 \mathrm{G}++(\mathrm{d}, \mathrm{p})^{32}$ basis set for all atoms except iodine, for which the DGDZVP ${ }^{33}$ basis set was used. The interaction energies were calculated at the same level without $(\Delta E)$ and with $\left(\triangle E_{B S S E}\right)$ correction for the BSSE using the Boys-Bernardi counterpoise technique, by subtracting the electronic energies of the isolated partners from the electronic energy of the noncovalent complex. ${ }^{34} \mathrm{NCI}$ analysis was performed using NCIPLOT software. ${ }^{21}$ A density cutoff of $\rho=0.1$ a.u. was applied. Threedimensional plots were created taking an isovalue of 0.5 for the reduced density gradient (s) and coloring in the $[-0.50 .5]$ a.u. $\operatorname{sign}\left(\lambda_{2}\right) \rho$ range using VMD software. ${ }^{35}$

\section{Results and Discussion}

The remarkable directionality of halogen bonding allows the structure and geometry of the resulting supramolecular architectures to be anticipated, with a reasonably high degree of accuracy, from the structure and geometry of the self-assembling elements. In the literature there are numerous examples in which bidentate halogen-bonding donors self-assemble with ditopic halogen-bonding acceptors to form infinite chains where the donor and acceptor alternate along the chains, thus linear building blocks afford linear infinite chains while angular modules afford zig-zag chains. ${ }^{7,36-37}$ This is also the case when employing linear or angular bis(haloethynyl)benzene derivatives with linear or angular halogen bond acceptors, as shown in Scheme 1. 
As mentioned in the introduction, the electron density distributionof haloethynylbenzene derivatives may lead to new supramolecular synthons. These edge-to-edge synthons, as shown in Chart 1, may give rise to2D and $3 \mathrm{D}$ architectures through weak $\mathrm{C}-\mathrm{H} \cdots \mathrm{X}(\mathrm{X}=\mathrm{I}, \mathrm{Br})$ and/or $\mathrm{C}-\mathrm{H} \cdots \pi_{(\mathrm{alkyne})}$ hydrogen bonds in combination with strong halogen bonds.

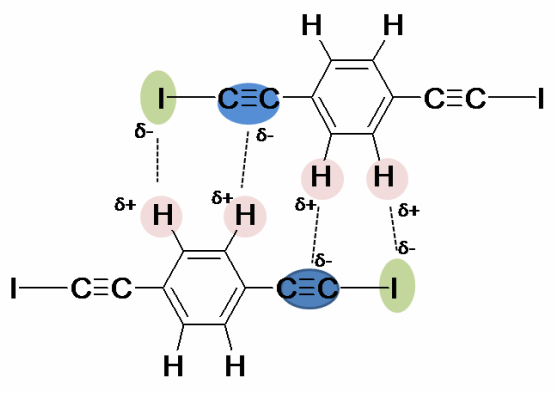

\section{Chart 1.}

With the aim of supporting our hypothesis, that bis(haloethynyl)benzene derivatives can promote edge-to-edge interactions giving rise to two-dimensional organizations, different intermolecular contacts in the arrays were systematically investigated beyond the sum of the van der Waals radii, since it has been noted that the use of the sum of van der Waals radii as a cut-off parameter to assess and evaluate weak $\mathrm{C}-\mathrm{H} \cdots \mathrm{X}$ hydrogen bonds is not recommended and should not be taken into account. $^{38}$

In halogen-bonded complexes 1 to 7 all XB donors and acceptors form two halogen bonds, despite the fact that propanone has only one acceptor atom and HTMA has four. Halogen bond distances, angles and reduction ratios, defined as $\mathrm{rr}=d_{X \cdots Y} / R_{v d W}(X)+R_{v d W}(Y)$, in these complexes are gathered in Table 2.

Table 2. Halogen bonds distances, angles and reduction ratios of the supramolecular polymers 1 to 7

\begin{tabular}{cllllll}
\hline Compound & $\mathbf{C}-\mathbf{X} \cdots \mathbf{Y}$ & Sym. equivalence & $\mathbf{d}(\mathbf{C}-\mathbf{X}) \AA$ & $\mathbf{d}(\mathbf{I} \cdots \mathbf{Y}) \boldsymbol{\AA}$ & \multicolumn{2}{c}{$<(\mathbf{C X Y}) \mathbf{D e g} . \mathbf{r r}$} \\
\hline $\mathbf{1}$ & $\mathrm{C}(1)-\mathrm{I}(1) \cdots \mathrm{N}(1)$ & $-1+\mathrm{x}, \mathrm{y},-1+\mathrm{z}$ & 2.035 & 2.729 & 178.4 & 0.77 \\
$\mathbf{2}$ & $\mathrm{C}(1)-\mathrm{Br}(1) \cdots \mathrm{N}(1)$ & $\mathrm{x}, \mathrm{y}, \mathrm{z}$ & 1.810 & 2.747 & 178.54 & 0.81 \\
$\mathbf{3}$ & $\mathrm{C}(1)-\mathrm{I}(1) \cdots \mathrm{N}(1)$ & $1 / 2-\mathrm{x},-1 / 2-\mathrm{y}, 1-\mathrm{z}$ & 2.024 & 2.722 & 177.48 & 0.77 \\
$\mathbf{4}$ & $\mathrm{C}(1)-\mathrm{I}(1) \cdots \mathrm{N}(1)$ & $1-\mathrm{x}, 1 / 2+\mathrm{y}, 1-\mathrm{z}$ & 2.27 & 2.785 & 172.9 & 0.79 \\
$\mathbf{5}$ & $\mathrm{C}(1)-\mathrm{I}(1) \cdots \mathrm{O}(1)$ & $2-\mathrm{x}, 1 / 2+\mathrm{y}, 2-\mathrm{z}$ & 2.011 & 2.929 & 177.9 & 0.84
\end{tabular}




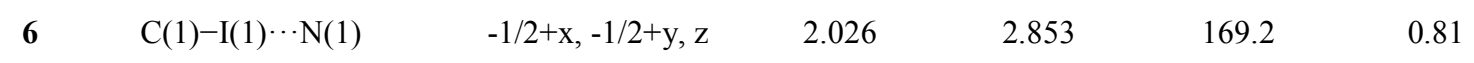

$\begin{array}{lllllll}7 & \mathrm{C}(1)-\mathrm{I}(1) \cdots \mathrm{N}(2) & 2-\mathrm{x}, 1-\mathrm{y}, 1-\mathrm{z} & 2.027 & 2.841 & 168.8 & 0.80\end{array}$

$\begin{array}{llllll}\mathrm{C}(10)-\mathrm{I}(2) \cdots \mathrm{N}(1) & 1 / 2-\mathrm{x},-1 / 2+\mathrm{y}, 1 / 2-\mathrm{z} & 2.019 & 2.815 & 175.0 & 0.80\end{array}$

As can be seen from the results in Table 2 the halogen bond distances are: $\mathrm{C}-\mathrm{Br} \cdots \mathrm{N}, 2.747 \AA$, $\mathrm{C}-\mathrm{I} \cdots \mathrm{O} 2.929 \AA$ and $\mathrm{C}-\mathrm{I} \cdot \cdot \mathrm{N}$ ranging from 2.722 to $2.853 \AA$. All of these distances are shorter than the sum of the van der Waals radii and correspond to a reduction ratio ranging from 0.77 to 0.84 . The $\mathrm{C}-\mathrm{X} \cdots \mathrm{Y}(\mathrm{X}=\mathrm{I}, \mathrm{Br} ; \mathrm{Y}=\mathrm{N}, \mathrm{O})$ angles are in all cases almost linear, with values ranging from 168.8 to $178.5^{\circ}$.

The cocrystals 1 to 3 are formed by the same XB acceptor (BPE). Cocrystals $\mathbf{1}$ and $\mathbf{2}$ were prepared with two different linear halogen donors, namely an iodo-derivative ( $p$-BIB) in $\mathbf{1}$ and a bromoderivative ( $p$-BBrB) in $\mathbf{2}$. The halogen donors in cocrystals $\mathbf{1}$ and $\mathbf{3}$ are both iodo-derivatives but with different geometries, i.e., linear for $p$-BIB (1) and angular for $m$-BIB (3). The comparison of halogen bonding in $\mathbf{1}\left(\mathrm{C}_{s p}-\mathrm{I} \cdots \mathrm{N}\right), \mathbf{2}\left(\mathrm{C}_{s p}-\mathrm{Br} \cdots \mathrm{N}\right)$ and $\mathbf{3}\left(\mathrm{C}_{s p}-\mathrm{I} \cdots \mathrm{N}\right)$ shows the same reduction ratio (0.77) in the case of linear $(p$-BIB, $\mathbf{1})$ and angular $(m$-BIB, 3$)$ iodo-based XB donors and a higher ratio in 2 (0.81), where the halogen atom is bromine $(p-\mathrm{BBrB})$. This last finding is consistent with halogen bonding reduction ratios described previously in 1,4-diiodotetrafluorobenzene $\operatorname{BPE}(0.78)^{40}$ and 1,4dibromotetrafluorobenzene $\cdot \mathrm{BPE}(0.84)$ cocrystals $^{41}$ and also with the $\mathrm{V}(\mathrm{r})$ maximum positive value calculated for the iodo-substituent $\left(172.4 \mathrm{~kJ} \mathrm{~mol}^{-1}\right)$ in 1-iodoethynyl-4-iodobenzene and the less polarizable bromo-substituent $\left(147.1 \mathrm{~kJ} \mathrm{~mol}^{-1}\right)$ in 1-bromoethynyl-4-iodobenzene. ${ }^{10}$ Furthermore, comparison of the halogen bond distances in the aforementioned BPE cocrystals with the iodo-XB donors $p$-BIB and 1,4-diiodotetrafluorobenzene ${ }^{40}$ shows that in both cases the distances are similar, with values of 2.729 and $2.768 \AA$, respectively. However, in the case of bromo-XB donors the halogen bonding distance is significantly shorter in cocrystal $\mathbf{2}$, which contains $p$ - $\mathrm{BBrB}$ as the coformer $(2.747 \AA)$, than in the 1,4-dibromotetrafluorobenzene-BPE (2.814 $\AA)$ cocrystal. As a consequence, the bromo-substituent is more strongly affected by a triple bond moiety than it is by the 
proximity of a perfluorinatedbenzene ring, thus making the bromoethynyl moiety a useful XB donor in crystal engineering. ${ }^{10,13,42}$

Cocrystals $\mathbf{4}$ and $\mathbf{5}$ are formed with the angular $m$-BIB iodo-donor and two angular ditopic XB acceptors pyridazine and propanone (with $s p^{2}$ hybridized nitrogen and oxygen, respectively). The halogen bond distance in 4 shows a reduction ratio of 0.79 , which is slightly higher than those observed in $\mathbf{1}$ and $\mathbf{3}$ - a finding that could be attributed to the low acceptor ability of the pyridazine due to the effect of the neighboring nitrogens. Cocrystal $\mathbf{5}$ had a longer halogen bond distance $\left(\mathrm{C}_{s p}-\mathrm{I} \cdots \mathrm{O}\right)(2.929 \AA)$ with a reduction ratio of 0.84 . This distance is slightly longer than those previously described for the $\mathrm{C}_{s p}-\mathrm{I}^{\cdots} \mathrm{O}_{s p^{2}} \quad 2.877 \quad \AA \quad$ interaction in the 1-[4(iodoethynyl)phenyl]ethanone structure. ${ }^{43}$ This fact may be due to oxygen forming a bifurcated halogen bond in an analogous way to that described for 4,4'-bis(dimethylamino)benzophenone and dimethylformamide in halogen-bonding cocrystal structures with 1,4-diiodo-2,3,5,6tetrafluorobenzene ${ }^{44}$ and diiodoacetylene, ${ }^{9}$ respectively.

Finally, cocrystals 6 and 7 allowed us to analyze the influence that the nitrogen atom hybridization has on the $\mathrm{XB}$ distance. The halogen bond distances $\left(\mathrm{C}_{s p}-\mathrm{I} \cdots \mathrm{N}\right)$ in these structures, in which the nitrogen atom has a $s p^{3}$ hybridization, are $2.853 \AA(6)$ and $2.841 \AA(7)$, respectively. Comparison of these distances with those in compounds $1(2.729 \AA), 3(2.722 \AA)$ and $4(2.785 \AA)$ - in which the hybridization is $s p^{2}$ - and with the distance in the previously described $p$-BIB $p$-decyloxybenzonitrile structure $^{24}$ (2.946 $\AA$ ) and 4-(iodoethynyl)benzonitrile structure ${ }^{43}(2.962 \AA)$, with $s p$ hybridization, shows an increasing trend in this parameter from $s p^{2}$ to $s p^{3}$ to $s p$. This change may be due to steric effects, considering that in the states of higher hybridization the local environment of electronegative atoms is generally tighter, so the halogen atom is less accessible.

\section{Halogen-bonded complexes 1 and 2: Linear XB donor and acceptor}


1,2-Bis(4-pyridyl)ethylene (BPE) forms isostructural 1:1 halogen-bonded complexes with XB donors $p$-BIB and $p$-BBrB. The two complexes crystallize in the triclinic $P-1$ space group and their asymmetric units consist of a half molecule of $p$ - $\mathrm{BIB}$ or $p$ - $\mathrm{BBrB}$ and a BPE half molecule situated on an inversion center. The combination of linear ditopic halogen bond donor ( $p$-BIB or $p$-BBrB) and acceptor (BPE) results in parallel linear assemblies propagated by $\mathrm{C}-\mathrm{X} \cdots \mathrm{N}(\mathrm{X}=\mathrm{I}, \mathrm{Br})$ halogen bonds. The two aromatic rings of BPE are almost coplanar and the planes that contain BPE and $p$ $\mathrm{BXB}(\mathrm{X}=\mathrm{I}, \mathrm{Br})$ are tilted with respect to one another by $26.2^{\circ}$ and $31.9^{\circ}$ in $\mathbf{1}$ and $\mathbf{2}$, respectively. Similar chains have been described in structures containing BPE and ditopic halogen bonding donors such as 1,4-diiodotetrafluorobenzene ${ }^{36}$ and 1,4-dibromotetrafluorobenzene. ${ }^{45}$

These chains in $\mathbf{1}$ and $\mathbf{2}$ are joined by weak $\mathrm{C}-\mathrm{H} \cdots \mathrm{X}(\mathrm{X}=\mathrm{I}, \mathrm{Br})$ and $\mathrm{C}-\mathrm{H} \cdots \pi_{(\mathrm{alkyne})}$ hydrogen bonds (Table 3) and this results in planes as shown in Figure 1, which stack donor over donor and acceptor over acceptor. This finding proves the validity of our approach to achieve two dimensional organizations by edge-to-edge interactions between haloethynylbenzene derivatives.

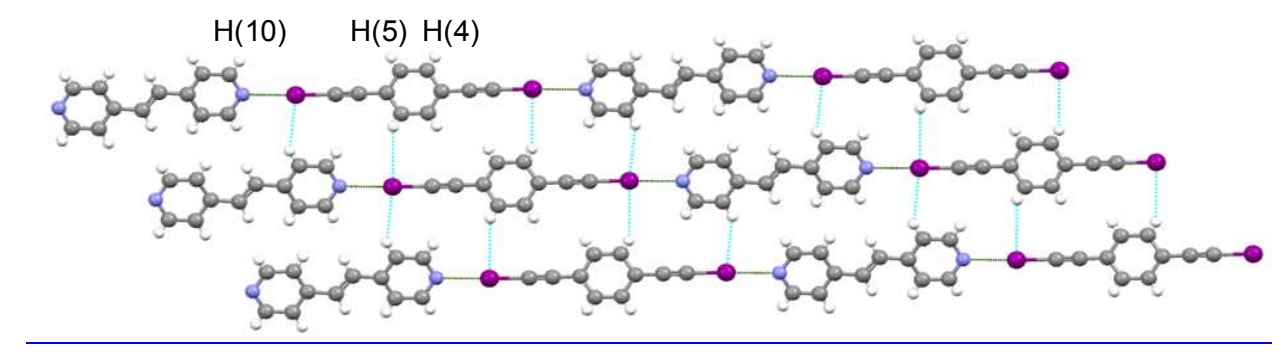

Figure 1. Layers in structure 1 formed by a combination of halogen bonds (green) and hydrogen bonds (blue).

Table 3. Hydrogen bond distances and angles in $\mathbf{1}$ and $\mathbf{2}$

\begin{tabular}{|c|c|c|c|c|c|c|}
\hline Compound & D-H $\cdots A$ & Sym. equivalence & $\mathrm{d}(\mathrm{D}-\mathrm{H}) \AA$ & $\mathrm{d}(\mathbf{H} \cdots \mathbf{A}) \AA$ & $d(D \cdots A) \AA$ & $<{\text { (DHA })^{0}}^{0}$ \\
\hline \multirow[t]{3}{*}{1} & $\mathrm{C}(4)-\mathrm{H}^{\cdots} \mathrm{I}(1)$ & $1+x, y, z$ & 0.83 & 3.33 & 4.083 & 151 \\
\hline & $\mathrm{C}(5)-\mathrm{H} \cdots \pi_{(\text {alkyne })}$ & $-\mathrm{x},-\mathrm{y}, 1-\mathrm{z}$ & 0.88 & 3.35 & 4.076 & 142 \\
\hline & $\mathrm{C}(10)-\mathrm{H} \cdots \mathrm{I}(1)$ & $-\mathrm{x},-\mathrm{y}, 1-\mathrm{z}$ & 0.92 & 3.44 & 4.171 & 138 \\
\hline \multirow[t]{3}{*}{2} & $\mathrm{C}(4)-\mathrm{H}^{\cdots} \cdot \mathrm{Br}(1)$ & $-1+x, y, z$ & 0.81 & 3.18 & 3.892 & 147 \\
\hline & $\mathrm{C}(5)-\mathrm{H}^{\cdots} \cdot \pi_{(\text {alkyne })}$ & $-\mathrm{x}, 2-\mathrm{y},-\mathrm{z}$ & 0.81 & 3.20 & 3.910 & 135 \\
\hline & $\mathrm{C}(10)-\mathrm{H} \cdots \mathrm{Br}(1)$ & $-x, 1-y, 1-z$ & 0.93 & 3.25 & 4.099 & 153 \\
\hline
\end{tabular}




\section{Halogen-bonded complex 3: Angular XB donor and linear acceptor}

The angular ditopic halogen bond donor $m$-BIB forms a 1:1 complex with linear ditopic halogen acceptor BPE (3). This complex crystallizes in the monoclinic $\mathrm{C} 2 / \mathrm{c}$ space group and the asymmetric unit consists of a BPE half-molecule on an inversion center and an $m$-BIB half molecule on a twofold axis.

Displaced halogen bonding zig-zag polymers along the baxis in $\mathbf{3}$ are joined by weak $\mathrm{C}-\mathrm{H} \cdots \mathrm{I}-\mathrm{C}$ hydrogen bonds between the XB donors (Table 4) that result in planes, as shown in Figure 2(a). The coplanar arrangement of $m$-BIB molecules in $\mathbf{3}$ leads to the proximity of the hydrogen atoms of the aromatic rings, which in turn causes the $\mathrm{C}-\mathrm{H} \cdots \mathrm{I}-\mathrm{C}$ hydrogen bond between the $m$-BIB molecules to be very weak $\left(3.88 \AA, 166^{\circ}\right)$. Finally, the planes are stacked $(3.2 \AA)$ and displaced by $8.6 \AA$ with respect to one another (Figure 2(b)).

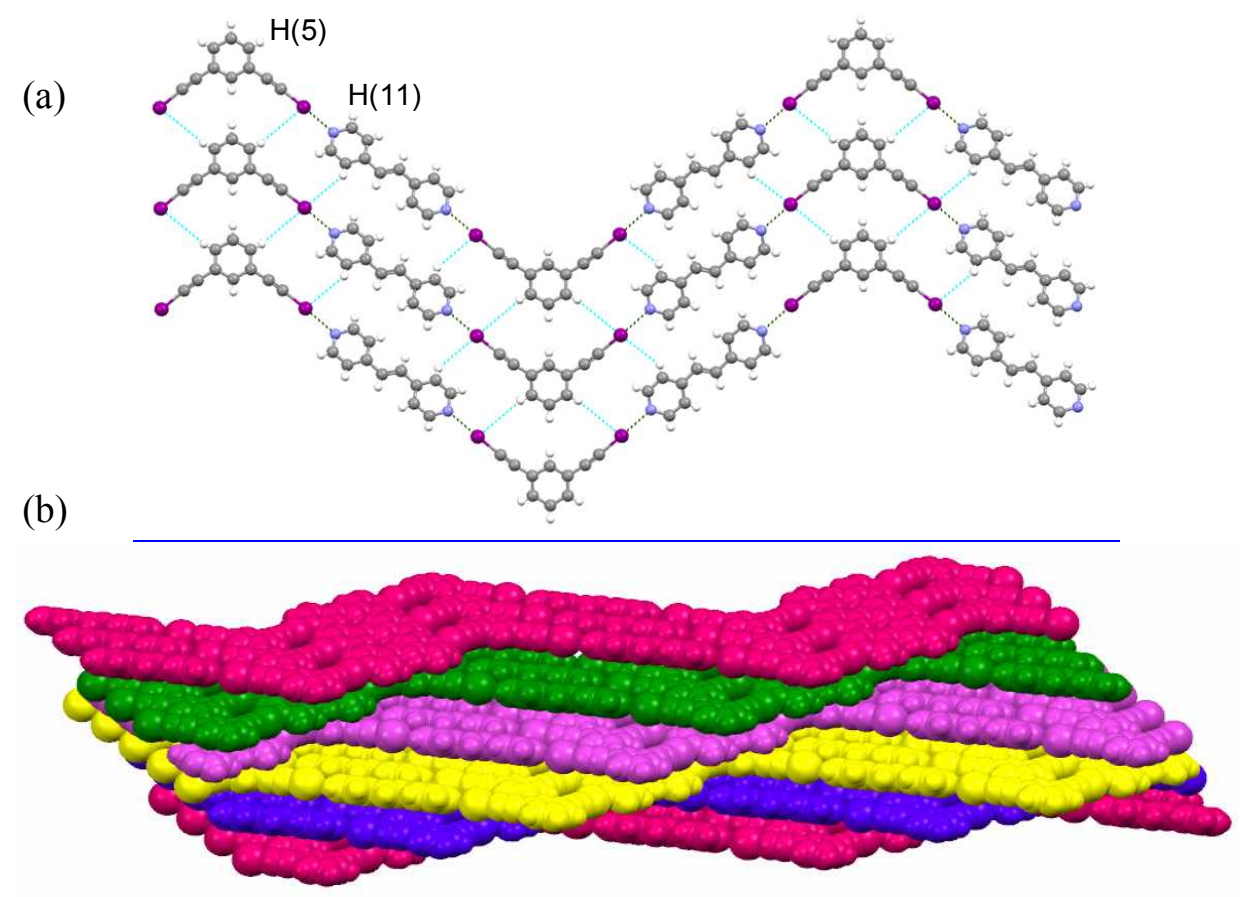

Figure 2. (a) Layers in structure 3 built by a combination of halogen bonds (green) and hydrogen bonds (blue); (b) displaced stacking planes.

Table 4. Hydrogen bond distances and angles in $\mathbf{3}$

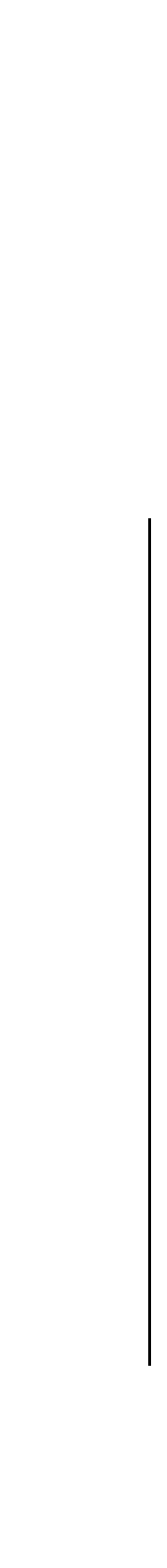


3

$$
\begin{array}{ll}
\mathrm{C}(5)-\mathrm{H} \cdots \mathrm{I}(1) & \mathrm{x}, 1+\mathrm{y}, \mathrm{z} \\
\mathrm{C}(11)-\mathrm{H} \cdots \mathrm{I}(1) & \mathrm{x}, \mathrm{y}, \mathrm{z}
\end{array}
$$

0.87

3.88

4.731

166

0.84

3.42

4.120

143

\section{Halogen-bonded complexes 4 and 5: Angular XB donor and acceptor}

Angular $m$-BIB forms 1:1 XB complexes with pyridazine and propanone and these crystallize in the orthorhombic Pnma space group (4) and in the monoclinic P2 $1 / n$ (5), respectively. The two asymmetric units consist of a half molecule of $m$-BIB and a half molecule of XB acceptor.

The crystal structures of $\mathbf{4}$ and $\mathbf{5}$ comprise zig-zag chains in which pyridazine (Figure 3(a)) and propanone (Figure 4) form two halogen bonds.

The halogen-bonded chains in $\mathbf{4}$ are dimerized by $\pi \cdots \pi$ stacking between pyridazine and $m$-BIB rings that are tilted at an angle of $4.0^{\circ}$. The shortest distance between rings is $3.38 \AA$ and between centroids it is $3.50 \AA$. The parallel dimerized chains are aligned along the $c$ axis but these are shifted by $2.23 \AA$ from one another, which prevents $\pi \cdots \pi$ interactions. These alignments are arranged in a parallel fashion as shown in Figure 3(b) and this organization is criss-cross with a similar one at an angle of $53.3^{\circ}$ to give rise to a $3 \mathrm{D}$ supramolecular network (Figure 3(c)). The structure is stabilized by a supramolecular synthon similar to that described for structure 3 but not coplanar (Figure 3(d)). This arrangement allows a closer tie between the $m$-BIB molecules and, consequently, the $\mathrm{C}-\mathrm{H} \cdots \mathrm{I}$ $\left(3.79 \AA, 133^{\circ}\right)$ hydrogen bond is shorter than that in $\mathbf{3}$. The hydrogen bond distances and angles of 4 and $\mathbf{5}$ are gathered in Table 5. 
(a)

(b)
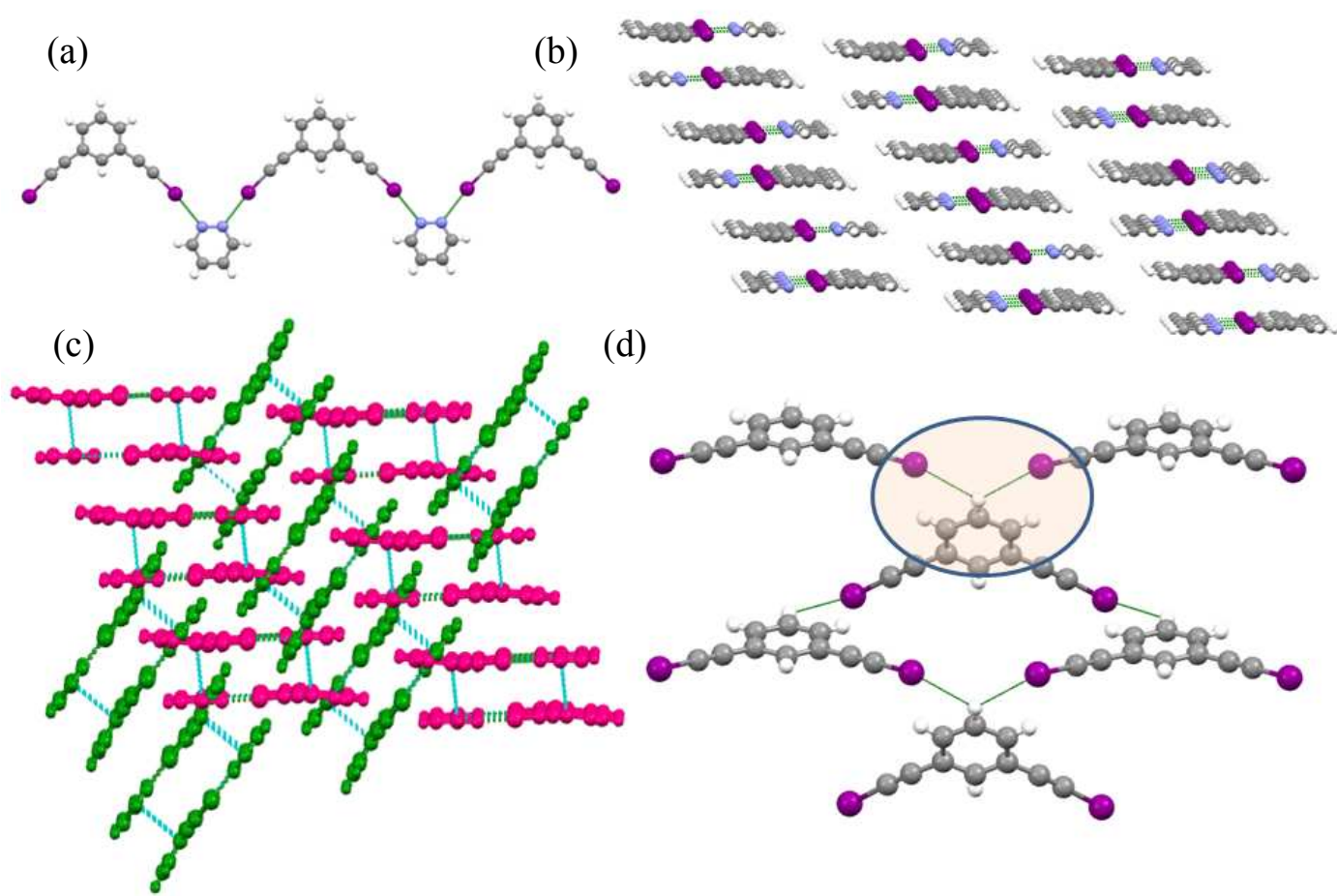

(d)

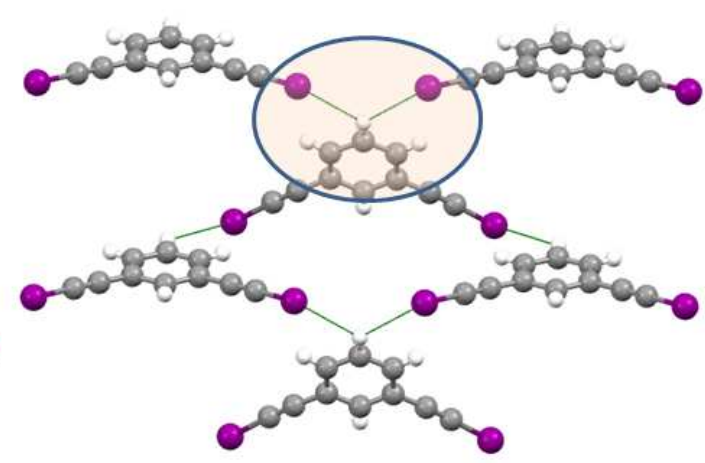

Figure 3. (a) XB Chains; (b) parallel alignments of dimerized halogen bonded chains; (c) criss-cross packing diagram with halogen bonds in green and $\pi \cdots \pi$ interactions in blue; (d) detail of the $\mathrm{C}-\mathrm{H} \cdots \mathrm{I}$ supramolecular synthon in 4 .

In structure $\mathbf{5}$ halogen bonded strands related by an inversion center give rise to ribbons through $\mathrm{C}-\mathrm{H} \cdots \mathrm{I}\left(3.51 \AA, 142^{\circ}\right)$ and $\mathrm{C}-\mathrm{H} \cdots \pi_{(\mathrm{alkyne})}\left(3.02 \AA, 162^{\circ}\right)$ hydrogen bonds between $m$-BIB molecules, as shown in Figure 4. A similar supramolecular synthon is present, although it was not described, in the structure of the 1,2-bis(iodoethynyl)benzene $\cdot 4-\left(\mathrm{N}, \mathrm{N}\right.$-dimethylamino)pyridine cocrystal ${ }^{12}$ and this shows that the halogen bond acceptors with oxygen atoms are also suitable for the formation of bidimensional arrangements through edge-to-edge interactions. Finally, ribbons are arranged in 2D arrays that stack along the $a$ axis. These arrays are shifted by $2.1 \AA$ from one another and this limits $\pi \cdots \pi$ stacking. 
Figure 4. 2D Arrangement in 5, stabilized by halogen bonds in green and hydrogen bonds in blue.

Table 5. Hydrogen bond distances and angles in $\mathbf{4}$ and $\mathbf{5}$

\begin{tabular}{lllllll}
\hline Compound & $\mathbf{D}-\mathbf{H} \cdots \mathbf{A}$ & Sym. equivalence & $\mathbf{d}(\mathbf{D}-\mathbf{H}) \AA$ & $\mathbf{d}(\mathbf{H} \cdots \mathbf{A}) \AA$ & $\mathbf{d}(\mathbf{D} \cdots \mathbf{A}) \AA$ & $<(\mathbf{D H A})^{\mathbf{0}}$ \\
\hline $\mathbf{4}$ & $\mathrm{C}(21)-\mathrm{H} \cdots \pi_{(\text {alkyne })}$ & $-1 / 2+\mathrm{x}, 1 / 2-\mathrm{y}, 1 / 2-\mathrm{z}$ & 0.92 & 2.903 & 3.83 & 177.5 \\
& $\mathrm{C}(5)-\mathrm{H} \cdots \mathrm{I}(1)^{(\mathrm{a})}$ & $1 / 2-\mathrm{x}, 1-\mathrm{y}, 1 / 2-\mathrm{z}$ & 0.97 & 3.28 & 4.00 & 133 \\
& $\mathrm{C}(4)-\mathrm{H} \cdots \mathrm{I}(1)$ & $-1 / 2+\mathrm{x}, \mathrm{y}, 1.5-\mathrm{z}$ & 0.98 & 3.79 & 4.512 & 133 \\
$\mathbf{5}$ & $\mathrm{C}(5)-\mathrm{H} \cdots \mathrm{I}(1)^{(\mathrm{a})}$ & $1-\mathrm{x}, 1-\mathrm{y}, 1-\mathrm{z}$ & 0.88 & 3.51 & 4.247 & 142 \\
& $\mathrm{C}(4)-\mathrm{H} \cdots \pi_{(\text {alkyne) }}$ & $1-\mathrm{x}, 1-\mathrm{y}, 1-\mathrm{z}$ & 0.96 & 3.022 & 3.949 & 162.3 \\
& & & & & &
\end{tabular}

\section{Halogen-bonded complexes 6 and 7: Linear XB donor and angular acceptor}

The angular halogen-bond acceptors crystallized with $p$-BIB include hexamethylenetetramine (HTMA) and, although this has four acceptors groups, it behaves as a ditopic system, and racemic 2,8-dimethyl-6H,12H-5,11-methanodibenzo[b,f]-[1,5]diazocine, Tröger's base (TB). In contrast to the halogen-bond acceptors described in previous sections, both HTMA and TB are not planar and their nitrogen atoms have $s p^{3}$ hybridization. HTMA and TB form 1:1 complexes with $p$-BIB and these crystallize in the orthorhombic $\mathrm{Cmcm}$ and the monoclinic $\mathrm{P} 2{ }_{1} / \mathrm{n}$ space groups, respectively. 
The asymmetric unit of $\mathbf{6}$ consists of a half molecule of HMTA and $p$-BIB and that of 7 consists of a TB and a $p$-BIB molecule.

The size and geometry of the HMTA and TB determine the dimensional features of the halogenbonded zig-zag polymers. Accordingly, the distances between two adjacent iodine atoms are $6.06 \AA$ and $6.46 \AA$, between two nitrogen atoms $21.47 \AA$ and $25.42 \AA$ and the angles formed by the planes containing two contiguous $p$-BIB are 59 and $74^{\circ}$ in 6 and 7 , respectively.

The halogen bond donors $p$-BIB in $\mathbf{6}$ are arranged in a herringbone-type fashion (along the $c$ axis) separated by layers of HMTA molecules. These layers are related by $\mathrm{C}(12)-\mathrm{H} \cdots \mathrm{N}(2)$ hydrogen bonds (3.690 $\AA, 162^{\circ}$ ) (see Figure 5). In addition, $p$-BIB molecules interact edge-to-edge to form the supramolecular synthon, highlighted in Figure 5, described in structure 1. Hydrogen bond distances and angles for $\mathbf{6}$ and $\mathbf{7}$ are gathered in Table 6.

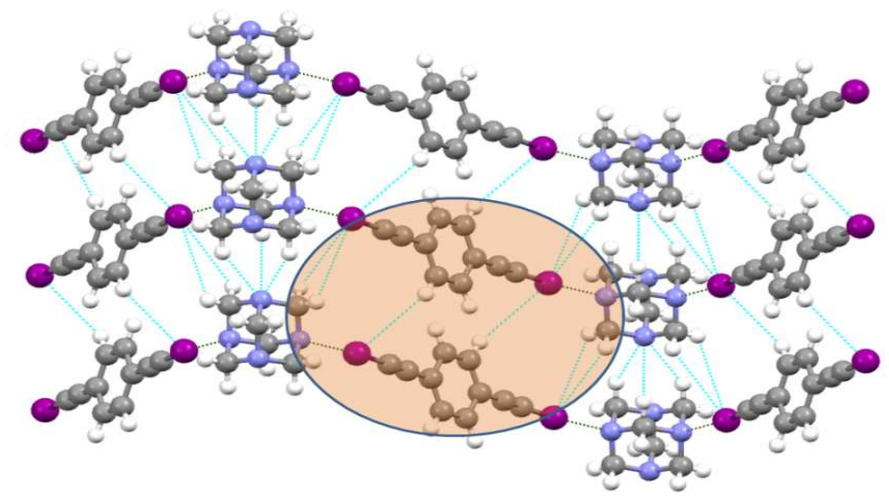

Figure 5. Packing diagram of the $p$-BIB·HMTA (5) complex formed by a combination of halogen bonds (green) and hydrogen bonds (blue).

TB core 1,5-diazabicyclo[1.3.3]nonane and the two attached aryl groups produce a rigid V-shaped molecule with a cleft angle of $99^{\circ}$ with an inherent $\mathrm{C}_{2}$-symmetric chirality (Scheme 1). Such framework stability, along with the relative ease of preparation and derivatization, offers an attractive starting point for a variety of functional materials. ${ }^{45-46}$ Despite this potential, only two TB 
cocrystal structures have been described to date and these were based on (-)-dibenzoyl-L-tartaric $\operatorname{acid}^{47}$ and TB. ${ }^{48}$

In the structure of 7 the strength and directionality of XB translates the exo-face to exo-face TB dimers (Figure 6(a)) stabilized by weak $\mathrm{C}_{s p 3}-\mathrm{H} \cdots \pi_{(\text {arene) }}$ hydrogen bonds $\left(2.78 \AA\right.$ and $\left.175^{\circ}\right)$ into $2 \mathrm{D}$ layers. These layers are built by rhombic units with a side length of $14 \AA$ (Figure 6(b)).

(a)

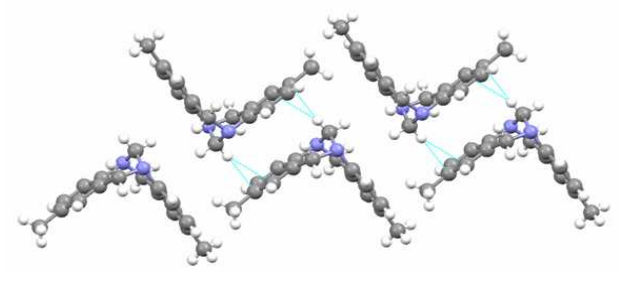

(b)

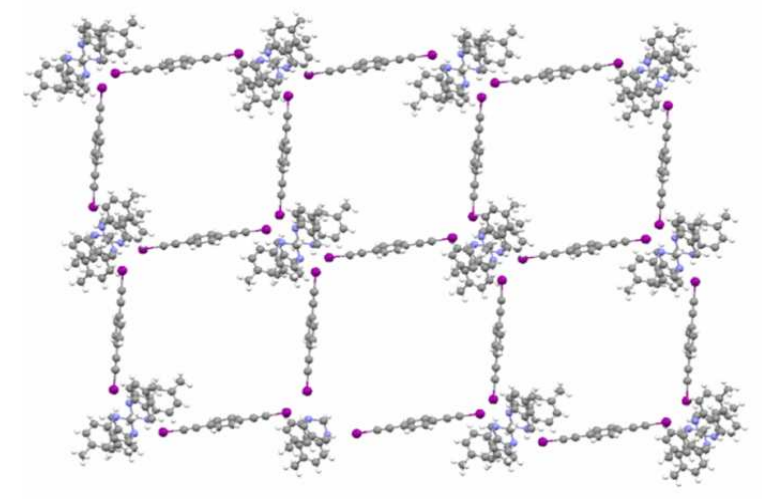

Figure 6. (a) Exo-face to exo-face TB dimers; (b) 2D rhombic layers with a $(4,4)$ topology in complex 4.

Thus, the sheets have large cavities that allow the formation of an entangled system by interpenetration of three other rhombic frameworks, as shown in Figure 7. The overall lattice is stabilized by weak TB $\mathrm{C}_{s p 3}-\mathrm{H}^{\cdots} \pi_{(\text {alkyne) }}\left(2.73 \AA\right.$ and $\left.162^{\circ}\right)$ and $p$-BIB $\mathrm{C}_{s p 2}-\mathrm{H} \cdots \pi_{(\text {alkyne) }}(2.89 \AA$ and $155^{\circ}$ ) hydrogen bonds. 


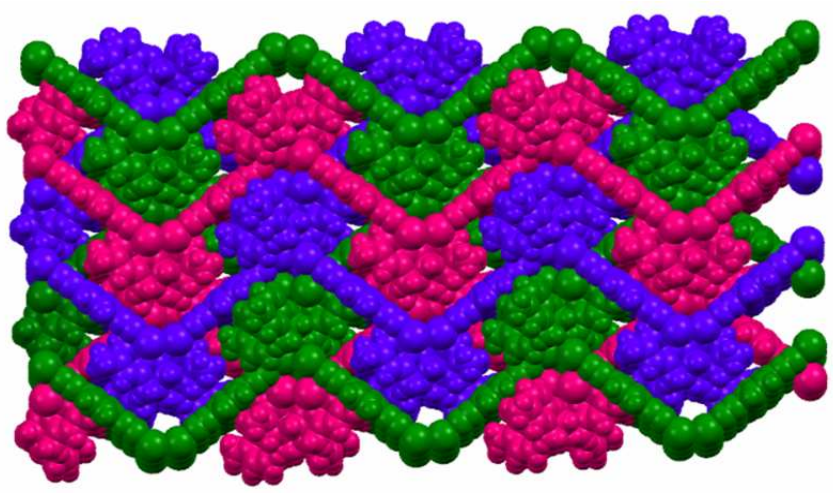

Figure 7. 3-Fold interpenetrated network in 7.

Table 6. Hydrogen bond distances and angles in 6 and 7

\begin{tabular}{cllllll}
\hline Compound & $\mathbf{D}-\mathbf{H} \cdots \mathbf{A}$ & Sym. equivalence & $\mathbf{d}(\mathbf{D}-\mathbf{H}) \AA$ & $\mathbf{d}(\mathbf{H} \cdots \mathbf{A}) \AA$ & $\mathbf{d}(\mathbf{D} \cdots \mathbf{A}) \AA$ & $<(\mathbf{D H A})^{\mathbf{o}}$ \\
\hline $\mathbf{6}$ & $\mathrm{C}(4)-\mathrm{H} \cdots \mathrm{I}(1)$ & $1 / 2+\mathrm{x}, 1 / 2+\mathrm{y}, \mathrm{z}$ & 1.00 & 3.45 & 4.352 & 151 \\
& $\mathrm{C}(10)-\mathrm{H} \cdots \mathrm{N}(2)$ & $1.5-\mathrm{x}, 1 / 2+\mathrm{y}, 1 / 2-\mathrm{z}$ & 1.07 & 3.04 & 3.968 & 146 \\
& $\mathrm{C}(12)-\mathrm{H} \cdots \mathrm{N}(2)$ & $1.5-\mathrm{x}, 1 / 2+\mathrm{y}, 1 / 2-\mathrm{z}$ & 1.08 & 2.64 & 3.69 & 162 \\
& $\mathrm{C}(10)-\mathrm{H} \cdots \mathrm{I}(1)$ & $1+\mathrm{x}, \mathrm{y}, \mathrm{z}$ & 1.07 & 3.48 & 3.911 & 111 \\
7 & $\mathrm{C}(26)-\mathrm{H} \cdots \pi_{\text {(alkyne) }}$ & $\mathrm{x}, \mathrm{y}, \mathrm{z}$ & 0.970 & 2.730 & 3.668 & 162.6 \\
& $\mathrm{C}(27)-\mathrm{H} \cdots \pi_{\text {(arene) }}$ & $1-\mathrm{x}, 1-\mathrm{y}, 1-\mathrm{z}$ & 0.970 & 2.780 & 3.747 & 174.9 \\
& $\mathrm{C}(4)-\mathrm{H} \cdots \pi_{\text {(arene) }}$ & $\mathrm{x}, \mathrm{y}, \mathrm{z}$ & $0.97(6)$ & 2.699 & 3.665 & 171.9 \\
& $\mathrm{C}(18)-\mathrm{H} \cdots \mathrm{I}(1)$ & $-1+\mathrm{x}, \mathrm{y},-1+\mathrm{z}$ & 0.970 & 3.405 & 4.230 & 142.2 \\
& $\mathrm{C}(23)-\mathrm{H} \cdots \mathrm{I}(1)$ & $-1+\mathrm{x}, \mathrm{y}, \mathrm{z}$ & 0.961 & 3.123 & 3.964 & 147.1 \\
$\mathrm{C}(24)-\mathrm{H} \cdots \mathrm{I}(2)$ & $1 / 2+\mathrm{x}, 1 / 2-\mathrm{y}, 1 / 2+\mathrm{z}$ & 0.930 & 3.351 & 4.124 & 142.0
\end{tabular}

\section{Hirshfeld surface analysis}

The intermolecular contacts in the crystal structures 1 to 7 were analyzed by Hirshfeld surface studies using the CrystalExplorer program. ${ }^{28}$ The size and shape of the Hirshfeld surfaces reflect the intermolecular contacts between atoms in a crystal and, in addition, they may encode different properties in a three-dimensional picture such as shape index or curvedness. This information can be summarized in a bidimensional fingerprint $\left(d_{i}, d_{e}\right)$ graph. $^{49}$ 
As expected from the different environments of each crystallographically independent halogenbonding donor ( $p$-BIB, $p$-BBrB or $m$-BIB) in structures 1 to 7 , their Hirshfeld surfaces and fingerprint plots are different. The main features of the fingerprint plots are related to stronger interactions. Consequently, halogen bonds $\mathrm{C}-\mathrm{X} \cdots \mathrm{N}(\mathrm{X}=\mathrm{I}, \mathrm{Br})$ appear as spikes denoted with the letter a in Figures $8(\mathrm{a})$ and $8(\mathrm{~b})$ and $\mathrm{C}-\mathrm{I} \cdots \mathrm{O}$ spikes are denoted as b in Figure 8(c). The presence of $\mathrm{C}-\mathrm{H} \cdots \mathrm{X}(\mathrm{X}=\mathrm{Br}, \mathrm{I})$ and $\mathrm{C}-\mathrm{H} \cdots \pi_{(\text {alkyne) }}$ hydrogen bonds that are characteristic of edge-to-edge supramolecular synthons that join halogen bond donors, as described in the crystal structures, is evidenced by the presence of peaks $\mathrm{c}$ and $\mathrm{d}$, respectively. However, the presence of these peaks may be due to interactions between the halogen bond donor and acceptor, as in compound 4 . The finger print plot of 3 shows characteristic peak e (Figure 8(a)) this is due to the close proximity of two hydrogen atoms when the supramolecular synthon shown in Figure 2(a) is formed.
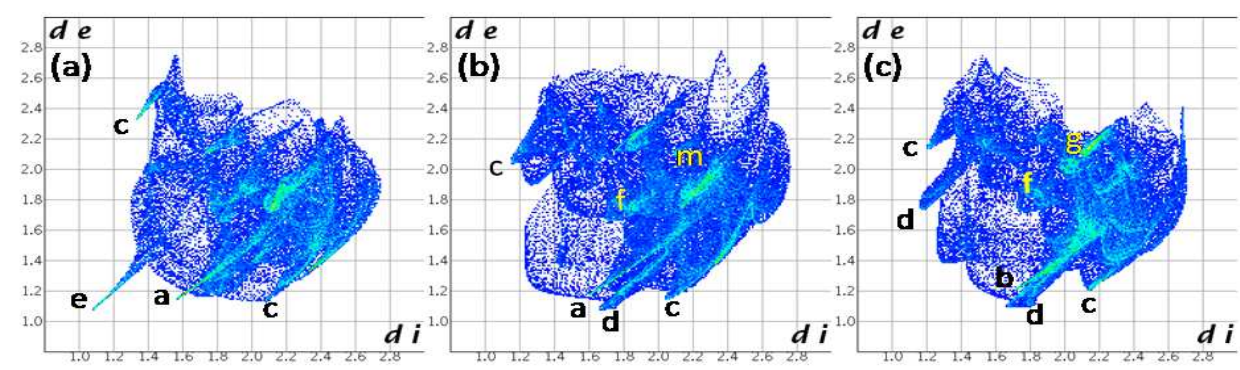

Figure 8. Fingerprint plots of halogen bonding donors in structures (a) 3, (b) $\mathbf{4}$ and (c) 5 .

One of the objectives when studying the formation of planar arrangements by edge-to-edge interactions is to promote the overlap of $\pi$-orbitals. On the Hirshfeld surface $\pi \cdots \pi$ interactions are manifested as a large flat region across the molecule, which is most clearly visible on the 'curvedness' surfaces (Figure 9(a)) as a pattern of red and blue triangles on the same region of the shape index surface (Figure 9(b)), and in fingerprint plots they appear as clear areas in the vicinity of $\left(d_{i}, d_{e}\right) \approx 1.8-2.0 \AA$ denoted by the letter $f$ in Figure 8 . 
(a)

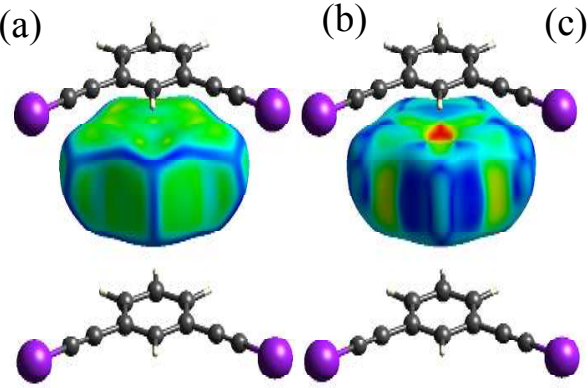

(c)

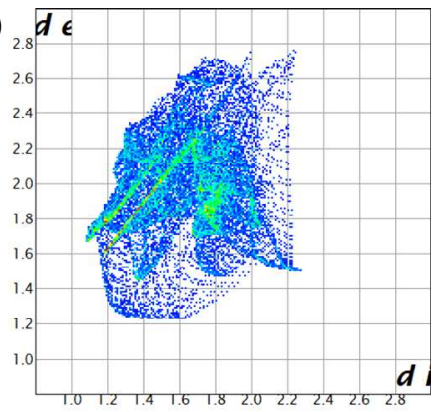

Figure 9. Curvedness (a), shape index (b) surfaces and (c) fingerprint plot of pyridazine in 4 showing the $\pi \cdots \pi$ interaction between halogen bond donors and acceptors.

In the fingerprint graphics of the halogen bond donors an area around $\left(d_{i}, d_{e}\right) \approx 1.8-2.0 \AA$ is not clearly observed. However, in the fingerprint graphics of flat halogen bond acceptors (BPE and pyridazine) this feature is more obvious (Figure 9(c)).

\section{Theoretical Calculations}

The energetic features of $\mathrm{C}-\mathrm{H} \cdots \mathrm{X}$ and $\mathrm{C}-\mathrm{H} \cdots \pi_{(\text {alkyne) }}$ non-covalent bonding between the halogen bond donors in the assembly of supramolecular architectures 1 to $\mathbf{6}$ were studied by DFT calculations on fragments extracted from crystal structures.

Single point energy calculations for these complex were performed using the B3LYP-D3 method combined with the DGDZVP basis set for iodine and the $6-311++G(d, p)$ for the other atoms. The uncorrected $(\Delta E)$ and corrected for BSSE $\left(\Delta E_{B S S E}\right)$ interaction energies of dimers are listed in Table 7. When the BSSE is not taken into account the interaction energies showed a marked energy overestimation (about 13\%), except for 2-D. Even so, the interaction energies of the complex gave sufficient negative values to indicate that these assemblies formed by non-covalent bonding are favorable. In most cases, the fragments comprise various nearly identical interactions related by symmetry elements in the crystal packing. These interactions cannot be separated when drawing fragments or ring patterns; hence, the energy values indicate the energy associated with the interplay of different interactions that cannot be calculated separately. 
Table 7. Uncorrected and corrected interaction energies of dimers ( $\Delta E$ and $\Delta E_{\mathrm{BSSE}}$, respectively, $\mathrm{kcal} \mathrm{mol}^{-1}$ ) calculated using B3LYP-D3/6-311++(d,p)-DGDZVP (single point calculations).

\begin{tabular}{lcc}
\hline Dimers $^{(a)}$ & $\boldsymbol{\Delta}$ & $\Delta \boldsymbol{E}_{\text {BSSE }}$ \\
\hline 1-D & -5.7 & -5.0 \\
2-D & -5.1 & -5.1 \\
3-D & -3.4 & -2.9 \\
4-D & -4.1 & -3.5 \\
5-D & -5.5 & -4.8 \\
6-D & -6.5 & -5.7
\end{tabular}

(a) $\mathrm{D}=$ Dimer (supramolecular synthon) in structures $\mathbf{1}$ to $\mathbf{6}$, see Figure 10 and Figure 11

The corrected interaction energies of supramolecular synthons between linear halogen bond donors, as depicted in Figure 10, are similar in all cases and around $5 \mathrm{kcal} \mathrm{mol}^{-1}$. The differences between the distances between planes and overlap between the subunits only translate into a slight variation of the interaction energy.

(a)
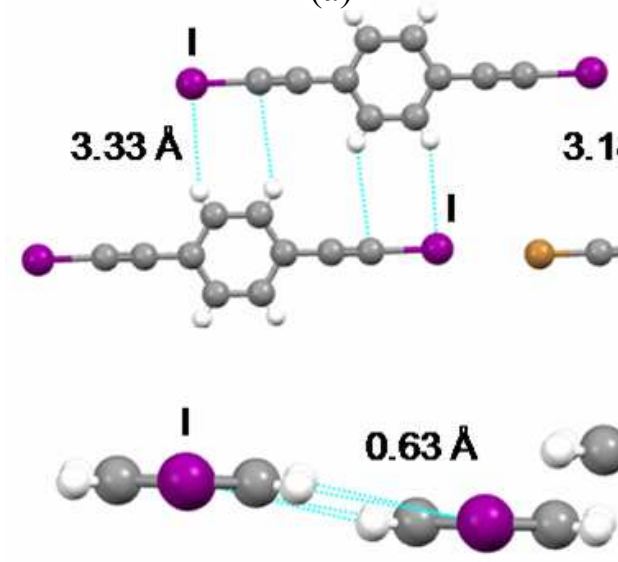

$-5.0 \mathrm{kcal} / \mathrm{mol}$ (b)

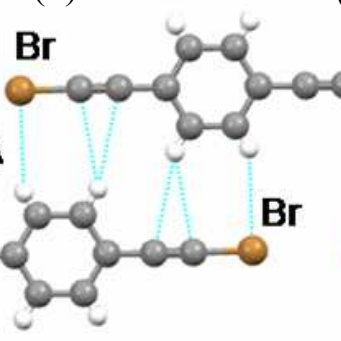

(c)

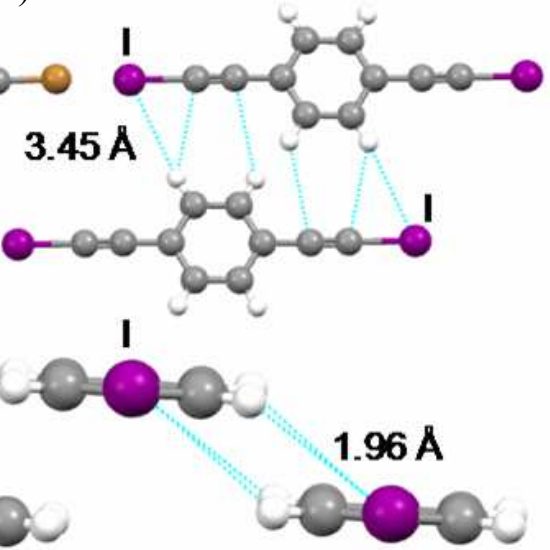

$-5.1 \mathrm{kcal} / \mathrm{mol}$

Figure 10. Hydrogen bond synthons and corrected interaction energies $\left(\Delta E_{\mathrm{BSSE}}\right)$ formed by $p$-BIB in structures 1 (1-D) (a) and 6 (6-D) (c) and $p$-BBrB in 2 (2-D) (b).

In compounds 3, 4 and $5 \mathrm{~m}$-BIB forms three types of supramolecular synthon (Figure 11), two of them are formed only by two $\mathrm{C}-\mathrm{H} \cdots \mathrm{I}$ hydrogen bonds with a corrected interaction energy of about 3 $\mathrm{kcal} \mathrm{mol}^{-1}$, and the other is joined by two $\mathrm{C}-\mathrm{H} \cdot \cdot \mathrm{I}$ and two $\mathrm{C}-\mathrm{H} \cdots \pi_{(\text {alkyne) }}$ hydrogen bonds with a 
higher stabilization energy of $4.8 \mathrm{kcal} \mathrm{mol}^{-1}$. Despite the weak energies, it has been demonstrated that the effects of these interactions on the crystal structure and packing are relevant.

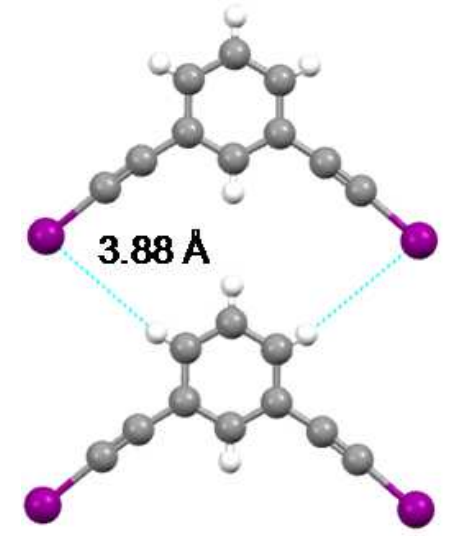

$\Delta \mathrm{E}=-2.9 \mathrm{kcal} / \mathrm{mol}$

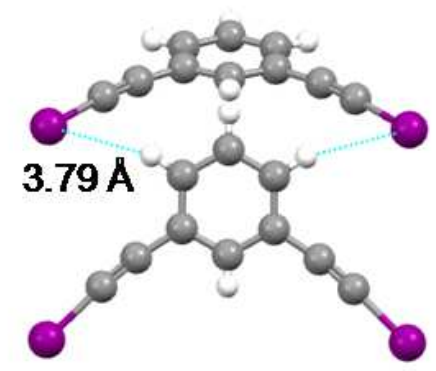

$\Delta \mathrm{E}=-3.5 \mathrm{kcal} / \mathrm{mol}$

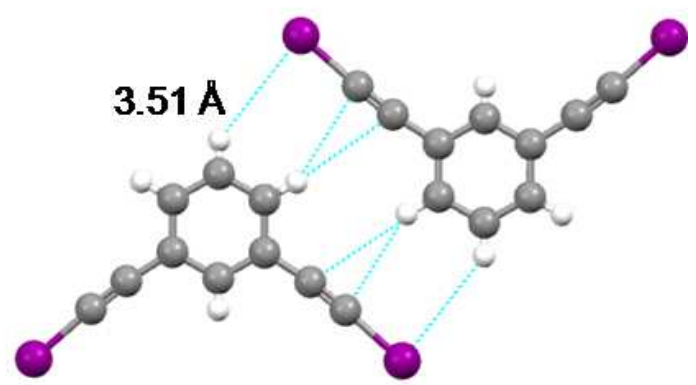

$\Delta \mathrm{E}=-4.8 \mathrm{kcal} / \mathrm{mol}$

Figure 11. Supramolecular synthons and corrected interaction energies ( $\left.\Delta E_{\mathrm{BSSE}}\right)$ formed by $m$-BIB in structures 3 (3-D)

(a), 4 (4-D) (b) and 5 (5-D) (c).

In order to complement information obtained from DFT calculations and obtain a deeper understanding of non-covalent interactions, NCI analyses were applied to the same dimers. This method uses the electron density, $\rho$, and its reduced gradient, $s(\rho)$, to discriminate between different kinds of non-covalent interactions, namely, attractive, van der Waals dispersive interactions and repulsive ones (as steric clashes). ${ }^{22}$ A continuous color code scheme based on second derivatives is applied within 3D plots so that strong attractive interactions are shown in blue, weak interactions (as dispersive ones) appear in green and strong repulsive interactions in red. This way, the method is expected to be suitable for visualize hydrogen bonding interactions. They will appear in blue with a very disk-shape, as they are localized interactions. NCI isosurfaces for dimers 1-D, 2-D and 6-D, that is, the ones with halogen atoms in para- position, are shown in Figure 12 top. For 1-D, NCI analysis reveals the presence of two attractive interactions between iodine and hydrogen atoms that appear as blue reduced discoidal surfaces, in this case corresponding to $\mathrm{C}-\mathrm{H} \cdots \mathrm{I}$ hydrogen bonds (Figure 10(a)). A similar profile is obtained for $\mathbf{2}-\mathbf{D}$, revealing the presence of two $\mathrm{C}-\mathrm{H} \cdots \mathrm{Br}$ hydrogen bonds. Moreover, two $\mathrm{C}-\mathrm{H} \cdots \pi_{(\text {alkyne) }}$ attractive interactions are detected in 2-D as a consequence of the 
monomers being closer than in 1-D. Two C-H $\cdots$ I hydrogen bonds are also revealed for 6-D. In addition, an attractive interaction is observed between two aromatic hydrogen atoms belonging to different subunits. ${ }^{50}$
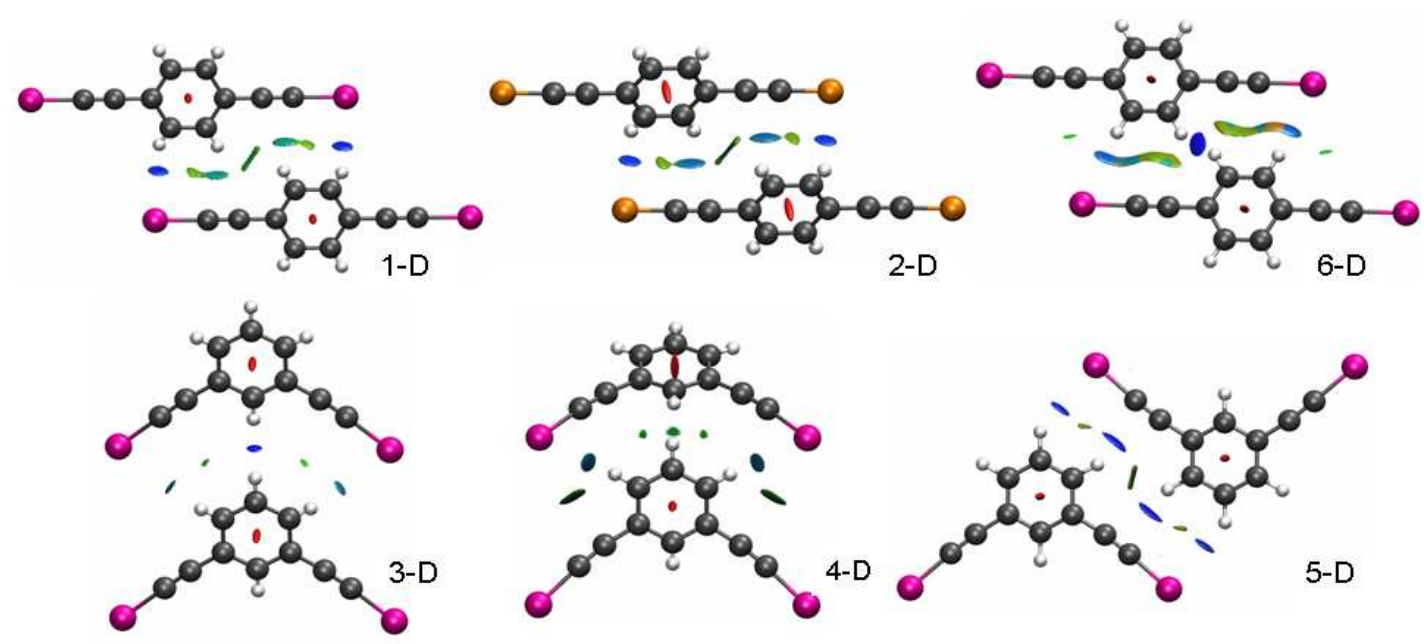

Figure 12. NCI isosurfaces for para- (top) and meta- (bottom) dimers performed at the B3LYP-D3/6$311 \mathrm{G}++(\mathrm{d}, \mathrm{p}) / \mathrm{DGDZVP}(\mathrm{I})$ level of theory

Figure 12 bottom shows NCI plots for dimers 3-D, 4-D and 5-D, that is, the ones with halogen atoms in meta- position. The NCI surfaces of all of them show two attractive interactions corresponding to $\mathrm{C}-\mathrm{H} \cdots \mathrm{I}$ hydrogen bonds. In addition, similar to that observed for 6-D, 3-D shows an interaction between aromatic hydrogens. In $4-\mathrm{D}$ are revealed two $\mathrm{I} \cdots \pi_{(\text {alkyne) }}$ van der Waals weak interaction shown by a diffuse green NCI surface. In 5-D, in addition to two C-H $\cdots$ I hydrogen bonds, two C-H $\cdots \pi_{(\text {alkyne) }}$ interactions are observed. These interactions had already been predicted by analyzing geometrical parameters and DFT interactions energies. NCI plot shows them as blue surfaces, however, they are more diffuse than those obtained for $\mathrm{C}-\mathrm{H} \cdots \mathrm{I}$ hydrogen bonds, showing that they are more delocalized interactions. The presence of this interactions is likely to be the stabilizing factor that increase the stabilization energy from about $3 \mathrm{kcal} \cdot \mathrm{mol}^{-1}$ in $3-\mathbf{D}$ and $\mathbf{4 - D}$ to almost $5 \mathrm{kcal} \cdot \mathrm{mol}^{-1}$ in $\mathbf{5 - D}$.

\section{Conclusions}


It has been demonstrated by the determination and analysis of seven co-crystals that bis(haloethynyl)benzene derivatives are suitable for the formation of two-dimensional structures.

The electron distribution of the haloethynylbenzene derivatives has two orthogonal areas, one of which is electrophilic along the carbon-halogen bond and another that is nucleophilic around the halogen atom and the triple bond. To date, more attention has been paid to the halogen-bonding donor character of haloethynylbenzene derivatives. Thus, $p$-BIB, $p$-BBrB and $m$-BIB are strong ditopic XB donors that form linear or angular polymers with ditopic linear or angular halogen bond acceptors such as BPE, pyridazine, HTMA and Tröger's base.

As we proposed, we have shown the complementarity of the bis(haloethynyl)benzene derivatives by $\mathrm{C}-\mathrm{H} \cdots \mathrm{X}$ and $\mathrm{C}-\mathrm{H} \cdots \pi_{(\text {alkyne) }}$ edge-to-edge hydrogen bonds that favor the formation of planar supramolecular synthons. It was determined, by means of DFT calculations that the negative interaction energies of such supramolecular synthons range from 2.9 to $5.7 \mathrm{kcal} \mathrm{mol}^{-1}$. These interactions were characterized by means of NCI analyses, confirming the existence of two attractive hydrogen bonds between XB donors. In spite of these weak energies, their effects on crystal structure and packing are relevant and, in combination with strong halogen bonds, these interactions have proven to be a useful strategy for the formation of two-dimensional arrangements in cocrystals with nitrogen and oxygen $\mathrm{XB}$ acceptors. Such materials are of great interest in the development of molecular organic materials.

\section{Supporting Information}

CCDC 1550397, 1550403, 1550404, 1550407, 1550410, 1550411 and 1550412 contain the supplementary crystallographic data for this paper. These data can be obtained free of charge via www.ccdc.cam.ac.uk/data_request/cif, or by emailing data_request@ccdc.cam.ac.uk, or by contacting The Cambridge Crystallographic Data Centre, 12, Union Road, Cambridge CB2 1EZ, UK; fax: +44 1223336033 . 


\section{Acknowledgment}

Thanks are given to Crystallography Service from the University of Zaragoza (Spain), University of Pais Vasco (Spain) and National University of Singapore. This work was supported by the Ministerio de Economía y Competitividad, under the projects MAT2014-55205-P, Fondo Europeo de Desarrollo Regional (FEDER) and Gobierno de Aragón. L. González thanks the Ministerio Economía y Competitividad and J. Munárriz thanks Ministerio de Educación Cultura y Deporte for a grant (FPU14/06003).

\section{References}

(1) Anthony, J. E. In Organic Electronics; Wiley-VCH Verlag GmbH \& Co. KGaA, 2006; pp 58-74.

(2) Dou, J.-H.; Zheng, Y.-Q.; Yao, Z.-F.; Yu, Z.-A.; Lei, T.; Shen, X.; Luo, X.-Y.; Sun, J.; Zhang, S.-D.; Ding, Y.-F.; Han, G.; Yi, Y.; Wang, J.-Y.; Pei, J. J. Am. Chem. Soc. 2015, 137, 15947-15956.

(3) Putta, A.; Mottishaw, J. D.; Wang, Z.; Sun, H. Cryst. Growth Des. 2014, 14, 350-356.

(4) Sokolov, A. N.; Friscic, T.; MacGillivray, L. R. J. Am. Chem. Soc. 2006, 128, 2806-2807; Maly, K. E. Cryst. Growth Des. 2011, 11, 5628-5633; Black, H. T.; Perepichka, D. F. Angew. Chem. Int. Ed. 2014, 53, 2138-2142; Frausto, F.; Smith, Z. C.; Haas, T. E.; Thomas, S. W., III Chem. Commun. 2015, 51, 8825-8828.

(5) Eichhorn, J.; Heckl, W. M.; Lackinger, M. Chem. Commun. 2013, 49, 2900-2902.

(6) Wu, W.; Jiang, H. Acc. Chem. Res. 2014, 47, 2483-2504.

(7) Sun, A. W.; Lauher, J. W.; Goroff, N. S. Science 2006, 312, 1030-1034.

(8) Yamamoto, H. M.; Kosaka, Y.; Maeda, R.; Yamaura, J.; Nakao, A.; Nakamura, T.; Kato, R. Acs Nano 2008, 2, 143-155; Luo, L.; Wilhelm, C.; Sun, A.; Grey, C. P.; Lauher, J. W.; Goroff, N. S. J. Am. Chem. Soc. 2008, 130, 7702-7709; Lieffrig, J.; Jeannin, O.; Fourmigue, M. J. Am. Chem. Soc. 2013, 135, 6200-6210; Szell, P. M. J.; Gabidullin, B.; Bryce, D. L. Acta Cryst. 2017, B73, 153-162.

(9) Perkins, C.; Libri, S.; Adams, H.; Brammer, L. CrystEngComm 2012, 14, 3033-3038.

(10) Aakeroey, C. B.; Baldrighi, M.; Desper, J.; Metrangolo, P.; Resnati, G. Chem. Eur. J. 2013, 19, 16240-16247.

(11) Le Questel, J.-Y.; Laurence, C.; Graton, J. CrystEngComm 2013, 15, 3212-3221.

(12) Bosch, E. Cryst. Growth Des. 2014, 14, 126-130.

(13) Aakeroey, C. B.; Wijethunga, T. K.; Desper, J.; Dakovic, M. Cryst. Growth Des. 2015, 15 , 3853-3861.

(14) Gilday, L. C.; Robinson, S. W.; Barendt, T. A.; Langton, M. J.; Mullaney, B. R.; Beer, P. D. Chem. Rev. 2015, 115, 7118-7195; Cavallo, G.; Metrangolo, P.; Milani, R.; Pilati, T.; Priimagi, A.; Resnati, G.; Terraneo, G. Chem. Rev. 2016, 116, 2478-2601.

(15) Politzer, P.; Lane, P.; Concha, M. C.; Ma, Y. G.; Murray, J. S. J. Mol. Model. 2007, 13, 305311; Politzer, P.; Murray, J. S.; Clark, T. Phys. Chem. Chem. Phys. 2010, 12, 7748-7757.

(16) Desiraju, G. R.; Steiner, T. The Weak Hydrogen Bond in Structural Chemistry and Biology; Oxford University Press: Oxford, 1999; Saha, S.; Rajput, L.; Joseph, S.; Mishra, M. K.; Ganguly, S.; Desiraju, G. R. CrystEngComm 2015, 17, 1273-1290.

(17) Desiraju, G. R. Angew. Chem. Int. Ed. 1995, 34, 2311-2327. 
(18) Guo, W.; Galoppini, E.; Gilardi, R.; Rydja, G. I.; Chen, Y.-H. Cryst. Growth Des. 2001, 1, 231 237; Barres, A. L.; El-Ghayoury, A.; Zorina, L. V.; Canadell, E.; Auban-Senzier, P.; Batail, P. Chem. Commun. 2008, 2194-2196.

(19) Linke, A.; Jungbauer, S. H.; Huber, S. M.; Waldvogel, S. R. Chem. Commun. 2015, 51, 20402043.

(20) Jungbauer, S. H.; Walter, S. M.; Schindler, S.; Rout, L.; Kniep, F.; Huber, S. M. Chem. Commun. 2014, 50, 6281-6284.

(21) Johnson, E. R.; Keinan, S.; Mori-Sanchez, P.; Contreras-Garcia, J.; Cohen, A. J.; Yang, W. T. J. Am. Chem. Soc. 2010, 132, 6498-6506.

(22) Contreras-Garcia, J.; Johnson, E. R.; Keinan, S.; Chaudret, R.; Piquemal, J. P.; Beratan, D. N.; Yang, W. T. J. Chem. Theory Comput. 2011, 7, 625-632.

(23) Lane, J. R.; Contreras-Garcia, J.; Piquemal, J. P.; Miller, B. J.; Kjaergaard, H. G. J. Chem. Theory Comput. 2013, 9, 3263-3266; Lepetit, C.; Poater, J.; Alikhani, M. E.; Silvi, B.; Canac, Y.; Contreras-Garcia, J.; Sola, M.; Chauvin, R. Inorg. Chem. 2015, 54, 2960-2969.

(24) Gonzalez, L.; Gimeno, N.; Tejedor, R. M.; Polo, V.; Ros, M. B.; Uriel, S.; Serrano, J. L. Chem. Mater. 2013, 25, 4503-4510.

(25) XSCANS In Siemens Analytical X-ray Instruments Inc.: Madison, Wisconsin, USA., 1994.

(26) In CrysAlys CCD Abingdon, England, 2006.

(27) Sheldrick, G. M. In SHELXTL, (Version 6.10) 2000.

(28) Wolff, S. K.; Grimwood, D. J.; McKinnon, J. J.; Turner, M. J.; Jayatilaka, D.; Spackman, M. A.: University of Western Australia, 2012.

(29) Frisch, M. J.; Trucks, G. W.; Schlegel, H. B.; Scuseria, G. E.; Robb, M. A.; Cheeseman, J. R.; Scalmani, G.; Barone, V.; Mennucci, B.; Petersson, G. A.; Nakatsuji, H.; Caricato, M.; Li, X.; Hratchian, H. P.; Izmaylov, A. F.; Bloino, J.; Zheng, G.; Sonnenberg, J. L.; Hada, M.; Ehara, M.; Toyota, K.; Fukuda, R.; Hasegawa, J.; Ishida, M.; Nakajima, T.; Honda, Y.; Kitao, O.; Nakai, H.; Vreven, T.; Montgomery, J. A., Jr.; Peralta, J. E.; Ogliaro, F.; Bearpark, M.; Heyd, J. J.; Brothers, E.; Kudin, K. N.; Staroverov, V. N.; Kobayashi, R.; Normand, J.; Raghavachari, K.; Rendell, A.; Burant, J. C.; Iyengar, S. S.; Tomasi, J.; Cossi, M.; Rega, N.; Millam, J. M.; Klene, M.; Knox, J. E.; Cross, J. B.; Bakken, V.; Adamo, C.; Jaramillo, J.; Gomperts, R.; Stratmann, R. E.; Yazyev, O.; Austin, A. J.; Cammi, R.; Pomelli, C.; Ochterski, J. W.; Martin, R. L.; Morokuma, K.; Zakrzewski, V. G.; Voth, G. A.; Salvador, P.; Dannenberg, J. J.; Dapprich, S.; Daniels, A. D.; Farkas, Ö.; Foresman, J. B.; Ortiz, J. V.; Cioslowski, J.; Fox, D. J. In Gaussian, Inc; Gaussian, I., Ed.; Wallingford CT: USA, 2009.

(30) Lee, C. T.; Yang, W. T.; Parr, R. G. Phys. Rev. B 1988, 37, 785-789; Becke, A. D. J. Chem. Phys. 1993, 98, 5648-5652; Becke, A. D. J. Chem. Phys. 1993, 98, 1372-1377.

(31) Grimme, S.; Antony, J.; Ehrlich, S.; Krieg, H. J. Chem. Phys. 2010, 132.

(32) Hehre, W. J.; Radom, L.; R., S. P. V.; Pople, J. A.; Wiley: New York, 1986.

(33) Godbout, N.; Salahub, D. R.; Andzelm, J.; Wimmer, E. Can. J. Chem. 1992, 70, 560-571.

(34) Boys, S. F.; Bernardi, F. Mol. Phys. 1970, 19, 553-566.

(35) Humphrey, W.; Dalke, A.; Schulten, K. J. Mol. Graph. 1996, 14, 33-38.

(36) Walsh, R. B.; Padgett, C. W.; Metrangolo, P.; Resnati, G.; Hanks, T. W.; Pennington, W. T. Cryst. Growth Des. 2001, 1, 165-175.

(37) Syssa-Magale, J. L.; Boubekeur, K.; Palvadeau, P.; Meerschaut, A.; Schollhorn, B. CrystEngComm 2005, 7, 302-308; Aakeroey, C. B.; Welideniya, D.; Desper, J.; Moore, C. CrystEngComm 2014, 16, 10203-10209.

(38) Desiraju, G. R. Cryst. Growth Des. 2011, 11, 896-898.

(39) Bondi, A. J. Phys. Chem. 1964, 68, 441.

(40) Forni, A.; Metrangolo, P.; Pilati, T.; Resnati, G. Cryst. Growth Des. 2004, 4, 291-295.

(41) De Santis, A.; Forni, A.; Liantonio, R.; Metrangolo, P.; Pilati, T.; Resnati, G. Chem. Eur. J. 2003, 9, 3974-3983.

(42) Aakeroey, C. B.; Chopade, P. D.; Desper, J. Cryst. Growth Des. 2013, 13, 4145-4150. 
(43) Dumele, O.; Wu, D.; Trapp, N.; Goroff, N.; Diederich, F. Org. Lett. 2014, 16, 4722-4725.

(44) Syssa-Magale, J. L.; Boubekeur, K.; Schollhorn, B. J. Mol. Struct. 2005, 737, 103-107.

(45) Runarsson, O. V.; Artacho, J.; Warnmark, K. Eur. J. Org. Chem. 2012, 7015-7041.

(46) Sergeyev, S. Helv. Chim. Acta 2009, 92, 415-444; Dolensky, B.; Havlik, M.; Kral, V. Chem. Soc. Rev. 2012, 41, 3839-3858; Du, X.; Sun, Y.; Tan, B.; Teng, Q.; Yao, X.; Su, C.; Wang, W. Chem. Commun. 2010, 46, 970-972; Carta, M.; Malpass-Evans, R.; Croad, M.; Rogan, Y.; Jansen, J. C.; Bernardo, P.; Bazzarelli, F.; McKeown, N. B. Science 2013, 339, 303-307.

(47) Satishkumar, S.; Periasamy, M. Tetrahedron: Asymmetry 2006, 17, 1116-1119.

(48) Cross, J. T.; Rossi, N. A.; Serafin, M.; Wheeler, K. A. CrystEngComm 2014, 16, 7251-7258.

(49) Spackman, M. A.; Jayatilaka, D. CrystEngComm 2009, 11, 19-32.

(50) Fokin, A. A.; Gerbig, D.; Schreiner, P. R. J. Am. Chem. Soc. 2011, 133, 20036-20039; Alonso, M.; Woller, T.; Martin-Martinez, F. J.; Contreras-Garcia, J.; Geerlings, P.; De Proft, F. Chem. Eur. J. 2014, 20, 4931-4941. 
For Table of Contents Use Only

\title{
Two-dimensional arrangements of
}

\section{bis(haloethynyl)benzenes combining halogen and}

\section{hydrogen interactions}

\author{
Lucía González, ${ }^{\mathrm{a}, \mathrm{d}}$ Rosa MaríaTejedor, ${ }^{\mathrm{h}}$ Eva Royo, ${ }^{\mathrm{a}, \mathrm{d}}$ Blanca Gaspar, ${ }^{\mathrm{a}, \mathrm{d}}$ Julen Munárriz, ${ }^{\mathrm{c}, \mathrm{g}}$ Anjana
}

Chanthapally, ${ }^{\mathrm{d}}$ José Luis Serrano, ${ }^{\text {,ff }}$ Jagadese J.Vittal, ${ }^{\mathrm{d}}$ Santiago Uriel ${ }^{\mathrm{a}}{ }^{\text {* }}$

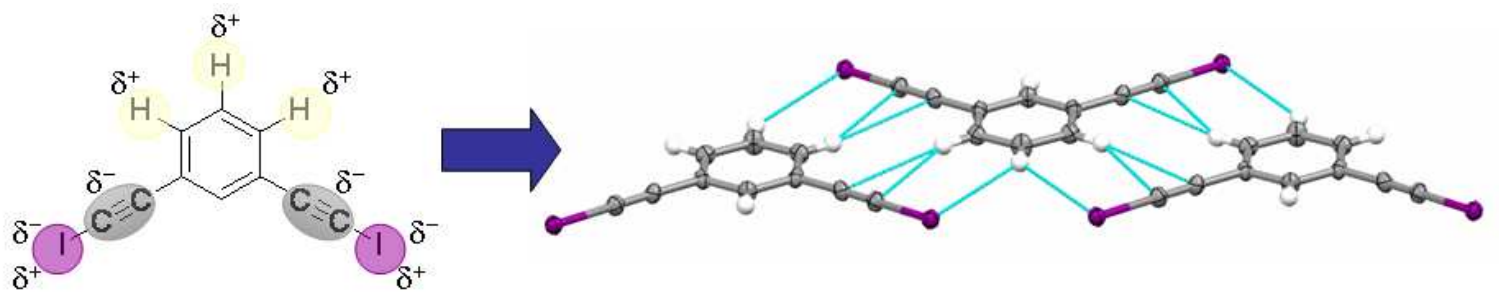

\begin{abstract}
The electronic distribution of some haloethynylbenzene derivatives may favour the formation of two-dimensional organizations by combining halogen and hydrogen bonds. In order to highlight this strategy we have prepared seven cocrystals and analyzed their structures. 1,4Bis(iodoethynyl)benzene $\quad(p$-BIB), $\quad$ 1,4-bis(bromoethynyl)benzene $\quad(p$-BBrB) and $\quad 1,3-$ bis(iodoethynyl)benzene ( $m$-BIB) were used as halogen bond donors and 1,2-bis(4-pyridyl)ethylene (BPE), pyridazine, propanone, hexamethylenetetramine (HTMA) and 2,8-dimethyl-6H,12H-5,11methanodibenzo[b,f][1,5]diazocine (Tröger's base, TB) were employed as halogen bond acceptors. The crystal structures of seven halogen-bonded complexes show $\mathrm{C}-\mathrm{X} \cdots \mathrm{Y}(\mathrm{X}=\mathrm{I}, \mathrm{Br} ; \mathrm{Y}=\mathrm{N}, \mathrm{O})$ distances shorter than the sum of the van der Waals radii and six of them contain the edge-to-edge $\mathrm{C}-\mathrm{H} \cdots \mathrm{X}(\mathrm{X}=\mathrm{I}, \mathrm{Br})$ supramolecular hydrogen bond synthon. The stabilization energies with BSSE
\end{abstract}


correction of hydrogen bond synthons have been determined by DFT calculations, and they are in the range 2.9 to $5.7 \mathrm{kcalmol}^{-1}$. To gain a deeper understanding of these interactions, Non-Covalent Interactions (NCI) methodology was also applied. 